\title{
Assimilation of ice motion observations and comparisons with submarine ice thickness data
}

\author{
Jinlun Zhang, D. R. Thomas, D. A. Rothrock, R. W. Lindsay, and Y. Yu \\ Polar Science Center, Applied Physics Laboratory, College of Ocean and Fishery Sciences, University of Washington, \\ Seattle, Washington, USA
}

\author{
R. Kwok \\ Jet Propulsion Laboratory, California Institute of Technology, Pasadena, California, USA
}

Received 26 June 2001; revised 9 October 2002; accepted 4 March 2003; published 3 June 2003.

[1] Aided by submarine observations of ice thickness for model evaluation, we investigate the effects of assimilating buoy motion data and satellite SSM/I (85 Ghz) ice motion data on simulation of Arctic sea ice. The sea-ice model is a thickness and enthalpy distribution model and is coupled to an ocean model. Ice motion data are assimilated by means of optimal interpolation. Assimilating motion data, particularly from drifting buoys, significantly improves the modeled ice motion, reducing the error to $0.04 \mathrm{~m} \mathrm{~s}^{-1}$ from $0.07 \mathrm{~m} \mathrm{~s}^{-1}$ and increasing the correlation with observations to 0.90 from 0.66 . Without data assimilation, the modeled ice moves too slowly with excessive stoppage. Assimilation leads to more robust ice motion with substantially reduced stoppage, which in turn leads to strengthened ice outflow at Fram Strait and enhanced ice deformation everywhere. Enhanced deformation doubles the production of ridged ice to an Arctic Ocean average of $0.77 \mathrm{~m} \mathrm{yr}^{-1}$, and raises the amount of ridged ice to half the total ice volume per unit area of $2.58 \mathrm{~m}$. Assimilation also significantly alters the spatial distribution of ice mass and brings the modeled ice thickness into better agreement with the thickness observed in four recent submarine cruises, reducing the error to $0.66 \mathrm{~m}$ from $0.76 \mathrm{~m}$, and increasing the correlation with observations to 0.65 from 0.45 . Buoy data are most effective in reducing model errors because of their small measurement error. $\mathrm{SSM} / \mathrm{I}$ data, because of their more complete spatial coverage, are helpful in regions with few buoys, particularly in coastal areas. Assimilating both SSM/I and buoy data combines their individual advantages and brings about the best overall model performance in simulating both ice motion and ice thickness. INDEX TERMS: 4207 Oceanography: General: Arctic and Antarctic oceanography; 3337 Meteorology and Atmospheric Dynamics: Numerical modeling and data assimilation; 4540 Oceanography: Physical: Ice mechanics and air/sea/ice exchange processes; KEYWORDS: sea ice modeling, data assimilation, optimal interpolation

Citation: Zhang, J., D. R. Thomas, D. A. Rothrock, R. W. Lindsay, Y. Yu, and R. Kwok, Assimilation of ice motion observations and comparisons with submarine ice thickness data, J. Geophys. Res., 108(C6), 3170, doi:10.1029/2001JC001041, 2003.

\section{Introduction}

[2] Sea ice in the polar oceans plays a significant role in the changing Earth climate system. The climatic importance of sea ice has led to many efforts to improve sea-ice models. Some efforts have aimed at improving sea-ice morphology, dynamics, and thermodynamics in the models [e.g., Maykut and Untersteiner, 1971; Thorndike et al., 1975; Semtner, 1976; Pritchard et al., 1977; Parkinson and Washington, 1979; Hibler, 1979; Ebert and Curry, 1993]. One particular example is the evolution of a twocategory sea-ice model, based on work by Hibler [1979], to a multicategory Eulerian thickness distribution sea-ice model, based on the thickness distribution theory of

Copyright 2003 by the American Geophysical Union. 0148-0227/03/2001JC001041\$09.00
Thorndike et al. [1975] and the numerical implementation of Hibler [1980]. The multicategory thickness distribution sea-ice model calculates ice thermodynamic growth and decay over a variety of ice thicknesses, explicitly simulates the ice ridging process that links ice deformation to a redistribution of ice thicknesses, and therefore better captures the essence of the coupling of dynamic and thermodynamic sea-ice processes than the two-category model. The Hibler [1980] thickness distribution model has been improved by Flato and Hibler [1995] to simulate the evolution of the thickness distributions of undeformed ice, ridged ice, and snow. It has been further improved by Zhang and Rothrock [2001] to incorporate the distribution of ice enthalpy. Zhang and Rothrock's [2001] thickness and enthalpy distribution (TED) model is able to conserve ice mass as well as thermal energy during ice advection, growth or decay, and ridging. 
[3] Other efforts to improve sea-ice modeling have aimed at assimilating observational data into the models. These took advantage of the great advances that have been made in polar observational capabilities in the last 2 decades. These advances have led to a rich collection of data on sea ice, including, among others, buoy observations of ice motion, satellite passive microwave observations of ice motion, and submarine observations of ice thickness. Some of these observations are of sufficient coverage and duration to have been effectively assimilated into sea-ice models with varying degrees of complexity [e.g., Thomas and Rothrock, 1989, 1993; Thomas et al., 1996; Meier and Maslanik, 1999; Meier et al., 2000]. Particularly, the study by Meier and Maslanik [1999] employed an optimal interpolation technique to assimilate ice motion data derived from passive microwave imagery acquired by the Special Sensor Microwave/Imager (SSM/I) [Agnew et al., 1997; Kwok et al., 1998; Liu and Cavalieri, 1998]. Their study was perhaps the first effort to assimilate observed ice motion data into a large-scale multicategory thickness distribution model in order to maximize the model accuracy. They were successful in obtaining improved ice motion output with reduced error. They also reported that assimilating SSM/I ice motion data induces physically unrealistic changes in ice thickness near the Greenland coast and Canadian Archipelago. However, it is unclear how unrealistic these changes are, and if there is any assimilationinduced improvement in ice thickness in other areas of the Arctic Ocean. The question is, if assimilation of ice motion data can reduce the error of modeled ice motion, does it also reduce the error of modeled ice thickness and to what degree? As mentioned before, an important feature of a thickness distribution model is its inclusion of the physics of ice ridging that strongly depends on ice deformation. What then is the role of ice deformation, within the context of data assimilation, in ice ridging and therefore in ice thickness?

[4] Armed with submarine observations of ice thickness for model evaluation, this study is aimed to address these questions. We carried out this study with a 12-category TED sea-ice model coupled with an ocean model. An optimal interpolation procedure is employed in the coupled iceocean model for a series of data-assimilation simulations using ice motion data either collected from buoy observations or derived from SSM/I 85-GHz imagery. The model components are described more fully in section 2. Section 3 describes the optimal interpolation assimilation procedure. Section 4 describes how the simulated ice motion, deformation, and thickness fields, with or without data assimilation, compare to buoy motion data and to recently available ice thickness data from submarines. In section 5 , we summarize the results.

\section{Model Description}

[5] The coupled ice-ocean model consists of two components: a 12-category TED sea-ice model and an ocean model. The models are coupled in such a way that heat, mass, and momentum are conserved. Some aspects of the sea-ice model are described in the following sections. The ocean model is based on the Bryan-Cox model [Bryan, 1969; Cox, 1984] with an embedded mixed layer of Kraus and Turner [1967]. Detailed information about the ocean model is given by Zhang [1993] [see also Zhang et al., 1998a, 1998b].

\subsection{Sea-Ice Model}

[6] The 12-category TED sea-ice model consists of five main components: a momentum equation that determines ice motion, a viscous-plastic ice rheology with an elliptical yield curve that determines the relationship between ice deformation and ice internal stress, a heat equation that determines ice growth/decay and ice temperature, two ice thickness distribution equations that conserve ice mass, and an enthalpy distribution equation that conserves ice thermal energy. The first two components are described in detail by Hibler [1979]. The ice momentum equation, using Ip's [1993] seasonally varying air drag coefficients and turning angles, is solved employing Zhang and Hibler's [1997] numerical model for ice dynamics. The heat equation is solved, over each category, using Winton's [2000] threelayer thermodynamic model, which divides the ice in each category into two layers of equal thickness beneath a layer of snow. The ice thickness distribution equations are described in detail by Flato and Hibler [1995] and briefly presented here. There are two conservation equations for thickness distributions of ridged ice and undeformed ice, respectively, which are written as

$$
\begin{gathered}
\frac{\partial g_{r}}{\partial t}=-\nabla \cdot\left(\mathbf{u} g_{r}\right)-\frac{\partial\left(f_{r} g_{r}\right)}{\partial h}+\psi_{r}+F_{r} \\
\frac{\partial g_{u}}{\partial t}=-\nabla \cdot\left(\mathbf{u} g_{u}\right)-\frac{\partial\left(f_{u} g_{u}\right)}{\partial h}+\psi_{u}+F_{u}
\end{gathered}
$$

where the subscript $r$ refers to ridged ice, the subscript $u$ refers to undeformed ice, $g_{r}(h)$ and $g_{u}(h)$ are the ridged and undeformed ice thickness distributions, respectively, $\mathbf{u}$ is ice velocity, $f_{r}$ and $f_{u}$ are ice growth rates, $\psi_{r}$ and $\psi_{u}$ are the redistribution functions, or source terms, that describe the change in thickness distribution due to ridging, and $F_{r}$ and $F_{u}$ are called source terms of lateral melting by Flato and Hibler [1995]. Note that $g(h)=g_{r}(h)+g_{u}(h)$ is defined here as the (total) ice thickness distribution which is a normalized probability density function. The parameters governing the ridging process, such as the frictional dissipation coefficient, the ridge participation constant, and shear ridging parameter, are given by Flato and Hibler (see their Table 3 for the standard case).

[7] The ice enthalpy distribution equation is written as [Zhang and Rothrock, 2001]

$$
\frac{\partial e}{\partial t}=-\nabla \cdot(\mathbf{u} e)-\frac{\partial(f e)}{\partial h}+H F_{L}+\Phi,
$$

where $e(h)=g(h) H(h)$ is the ice enthalpy distribution function, $H(h)=\int_{0}^{h} \rho c_{p} T(z, h) d z$ is ice enthalpy per unit area, $\rho$ is ice density, $c_{p}$ is ice heat capacity, $h$ is ice thickness, $T$ is ice temperature, $f=f_{r}=f_{u}$ is ice growth rate, $F_{L}=F_{r}+F_{u}$ is the total source term for lateral melting, and $\Phi$ is the enthalpy redistribution function.

[8] Accompanying the ice model is a snow model described in terms of snow thickness distribution, $g_{s}(h)$. 


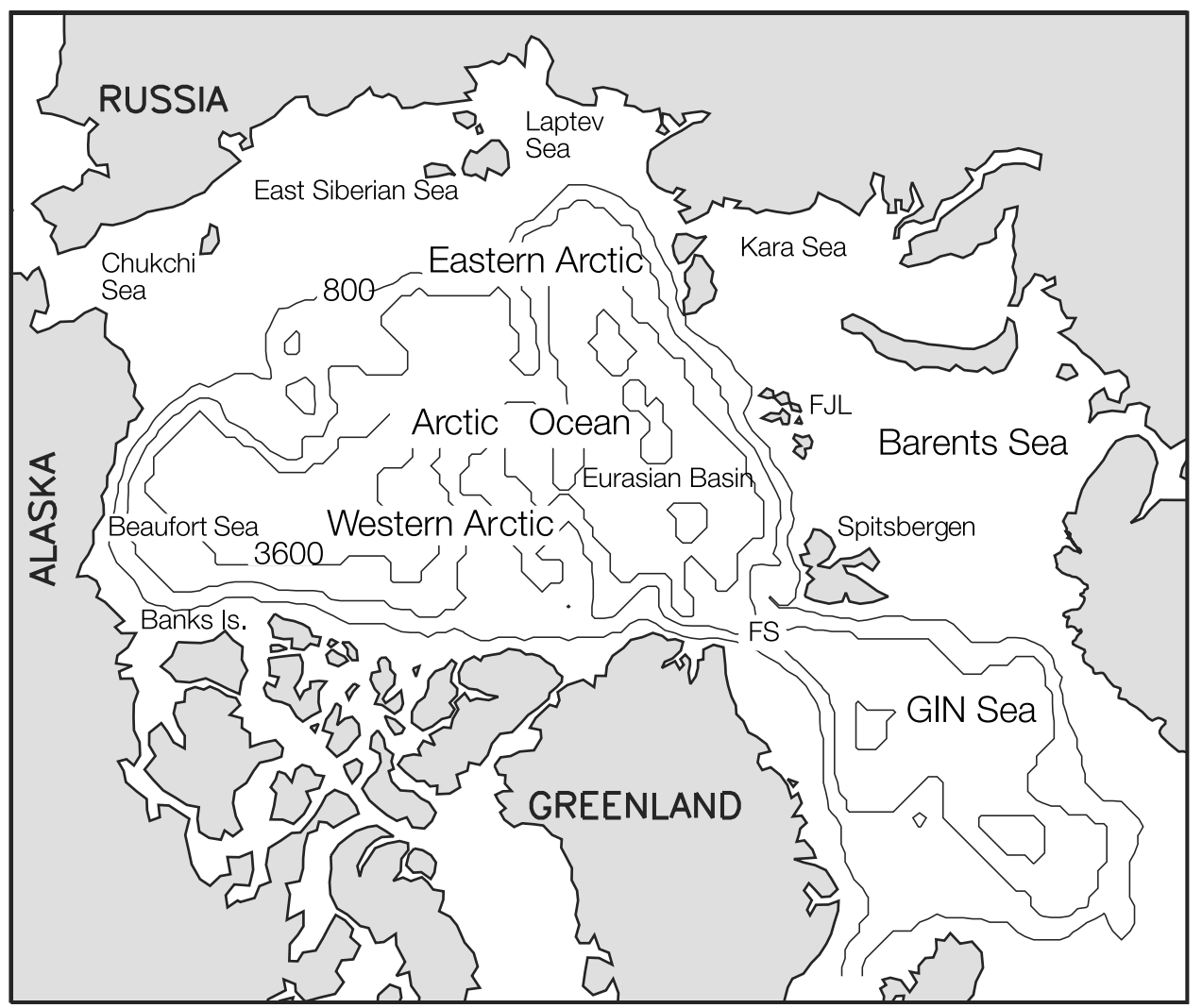

Figure 1. Model domain and bathymetry. Bathymetry contour interval is $1400 \mathrm{~m}$. Fram Strait and Franz Josef Land are marked as FS and FJL.

The snow conservation equation, the treatment of the snow thickness distribution, and the treatment of the thermodynamics at the ice/snow/ocean surface, including surface albedo, are determined by Flato and Hibler [1995, Appendix]. All the snow and ice thermodynamic parameters used here are the same as those used in the standard case of Flato and Hibler [1995].

\subsection{Numerical Framework and Surface Forcing}

[9] The model domain covers the Arctic, Barents, and GIN (Greenland-Iceland-Norwegian) seas (Figure 1). It has a horizontal resolution of $40 \mathrm{~km} \times 40 \mathrm{~km}, 21$ ocean levels, and 12 thickness categories each for undeformed ice, ridged ice, ice enthalpy, and snow. The partition of ice thickness categories are given by Zhang et al. [2000].

[10] Daily surface atmospheric forcing from 1992 to 1997 was used to drive the model. The forcing consists of geostrophic winds, surface air temperature, specific humidity, and longwave and shortwave radiative fluxes. (The forcing can be downloaded from the web site http://psc.apl. washington.edu/POLES/model_forcings/ModelForcings. html.) The geostrophic winds are calculated using the sea level pressure (SLP) fields from the International Arctic Buoy Program (IABP) [see Colony and Rigor, 1993]. The 2-m surface air temperature data are derived from buoys, manned drifting stations, and land stations [Rigor et al., 2000]. The specific humidity and longwave and shortwave radiative fluxes are calculated following the method of Parkinson and Washington [1979] based on the SLP and air temperature fields. Model input also includes river runoff and precipitation detailed by Hibler and Bryan [1987] and Zhang et al. [1998a].

\section{Data Assimilation}

\subsection{Ice Motion Data Sets}

[11] Buoy motion data and SSM/I 85 Ghz imageryderived ice motion data from 1992 to 1997 are used for data assimilation. The daily buoy data were provided by the IABP [Colony and Rigor, 1993]. On any given day from 1992 to 1997, there are between 10 and 30 buoy motion measurements irregularly and sparsely distributed in the Arctic. The uncertainty, or error standard deviation (SD), of the buoy data is $\sigma_{\text {bouy }}=0.007 \mathrm{~m} \mathrm{~s}^{-1}$ [Thorndike and Colony, 1980] [see also Meier et al., 2000].

[12] The Jet Propulsion Laboratory (JPL) Remote Sensing Group provides both 1-day and 2-day SSM/I ice motion data sets. The SSM/I data are gridded data and have better spatial coverage than the buoy data, but the number of available data vary temporarily (with no coverage in summer from June 1 to September 30). When compared to buoy displacements, the estimated uncertainty or error SD is $\sigma_{S S M / I}=0.058 \mathrm{~m} \mathrm{~s}^{-1}$ for the 1-day SSM/I data and 0.040 $\mathrm{m} \mathrm{s}^{-1}$ for the 2-day SSM/I data [Kwok et al., 1998]. When compared to 1-day buoy velocities, the estimated error SD of the 2-day SSM/I ice motion is either $0.045 \mathrm{~m} \mathrm{~s}^{-1}$ or $0.069 \mathrm{~m} \mathrm{~s}^{-1}$, depending on how it is aligned in time with the 1-day buoy motion [Lindsay, 2002]. The average error SD of the 2-day SSM/I ice motion, compared to 1-day buoy motion, is about $0.057 \mathrm{~m} \mathrm{~s}^{-1}$. 
[13] Which SSM/I data set should we use? To answer this question, we have conducted a series of model runs assimilating (following the data assimilation procedure described in section 3.2) either the 1-day data or the 2-day data with error SDs of $4 \times 0.058 \mathrm{~m} \mathrm{~s}^{-1}, 2 \times 0.058 \mathrm{~m} \mathrm{~s}^{-1}, 0.058 \mathrm{~m}$ $\mathrm{s}^{-1}, 0.058 / 2 \mathrm{~m} \mathrm{~s}^{-1}$, and $0.058 / 4 \mathrm{~m} \mathrm{~s}^{-1}$, respectively. We have found that, in comparisons with buoy drift data and submarine ice thickness data, assimilating the 2-day data generally reduces model errors in ice motion and thickness more substantially than assimilating the 1-day data. We have also found that the model agrees best with the observations when assimilating the 2-day data with an error $\mathrm{SD}$ of $0.058 \mathrm{~m} \mathrm{~s}^{-1}$. Therefore we have chosen the 2-day $\mathrm{SSM} / \mathrm{I}$ data with the error SD of $0.058 \mathrm{~m} \mathrm{~s}^{-1}$ for our standard data assimilation runs.

\subsection{Method of Optimal Interpolation}

[14] Our goal is to use observed ice velocity data to correct model estimates of ice velocities using an optimal interpolation (OI) assimilation procedure. The OI procedure has a long history of applications for meteorological data. It was also used for interpolating the sea level pressure observations of Arctic buoys into the sea level pressure fields [Thorndike and Colony, 1980], and temperature observations of buoys and land stations into the surface air temperature fields [Rigor et al., 2000]. It was further used by Meier and Maslanik [1999] and Meier et al. [2000] to assimilate ice motion observations. The procedure used in this study is, however, somewhat different from that of Meier et al. [2000]. The main difference is that the present procedure uses correlation functions that are Gaussian and positive definite, and allows ice divergence in a two-dimensional ice velocity field [Thorndike, 1986; Moritz, 1988].

[15] Let $U_{k}=(u, v)^{T}$ be the true ice velocity to be estimated at some location $X_{k}=\left(x_{k}, y_{k}\right)^{T}$. The modelevaluated ice velocity $\tilde{U}_{k}$ is a "first guess" of the true value at $X_{k}$ and $\widehat{U}_{i}$ is a set of $\mathrm{N}$ observations at arbitrary points $X_{i}$ $(\mathrm{i}=1, \ldots, \mathrm{N})$. An estimate of $U_{k}$ can be determined by a linear combination of the first guess and the observations

$$
\hat{U}_{k}=\widetilde{U}_{k}+A_{k}(\widehat{U}-\widetilde{U})
$$

where $A_{k}=\left(a_{k 1}, a_{k 2}, . ., a_{k N}\right)$ and $\widehat{U}-\widetilde{U}=\left[\left(\widehat{U}_{1}-\widetilde{U}_{1}\right)^{T}\right.$, $\left.\left(\widehat{U}_{2}-\widetilde{U}_{2}\right)^{T}, \ldots,\left(\widetilde{U}_{N}-\widetilde{U}_{N}\right)^{T}\right]^{T}$. The OI procedure allows the weights $A_{k}$ to be determined by a least squares minimization of the error variance of the estimate $\left\langle\hat{E}_{k} \hat{E}_{k}^{T}\right\rangle$ where $\hat{E}=U-\hat{U}$ and the angle brackets \langle\rangle denote the expected value operator. This leads to

$$
\begin{gathered}
a_{k j}=R_{k i}\left[R_{i j}+\delta_{i j} \sigma_{o b}^{2} / \sigma^{2}\right]^{-1} \\
\left\langle\hat{E}_{k} \hat{E}_{k}^{T}\right\rangle=\left(1-a_{k i} R_{k i}\right) \sigma^{2},
\end{gathered}
$$

where $R_{i j}=\left\langle\tilde{E}_{i} \tilde{E}_{j}^{T}\right\rangle / \sigma^{2}$ is the correlation between the first guess errors at locations $X_{i}$ and $X_{j}, \delta_{i j}$ is the Kroneker delta, $\sigma_{o b}$ is the error SD of observations, and $\sigma$ is the error SD of the first guess. Error variances of observations and the first guess are $\sigma_{o b}^{2}$ and $\sigma^{2}$, respectively. The correlation function $R_{i j}$ can be determined following
Thorndike [1986] for a homogeneous, isotropic two dimensional velocity field such that

$$
\begin{aligned}
R_{i j} & =R\left(X_{i}, X_{j}\right) \\
& =\left[\begin{array}{ll}
\cos ^{2} \theta B_{\|}(r)+\sin ^{2} \theta B_{\perp}(r) & \cos \theta \sin \theta\left(B_{\|}(r)-B_{\perp}(r)\right) \\
\cos \theta \sin \theta\left(B_{\|}(r)-B_{\perp}(r)\right) & \sin ^{2} \theta B_{\|}(r)+\cos ^{2} \theta B_{\perp}(r)
\end{array}\right]
\end{aligned}
$$

where $r^{2}=\left(x_{j}-x_{i}\right)^{2}+\left(y_{j}-y_{i}\right)^{2}, \cos \theta=\left(x_{j}-x_{i}\right) / r, \sin \theta=$ $\left(y_{j}-y_{i}\right) / r, B_{\|}(r)$ is the error correlation between components of velocity parallel to the line joining $X_{i}$ and $X_{j}$, and $B_{\perp}(r)$ is the error correlation between components of velocity perpendicular to that line. According to Thorndike [1986], $B_{\|}(r)$ and $B_{\perp}(r)$ are subject to a constraint that the variance of a vector consisting of a linear combination of ice velocities, such as that in equation (4), is non-negative. Such a constraint can be satisfied by introducing positive definite correlation functions of Gaussian forms, $B_{\|}(r)=\sigma^{2} \exp$ $\left[-(r / L)^{2}\right]$ and $B_{\perp}(r)=\sigma^{2}\left[1-2(r / L)^{2}\right] \exp \left[-(r / L)^{2}\right]$, where $L$ is the correlation length scale. These two correlation functions are associated with a nondivergent ice velocity field that can be determined by a stream function $\psi$ such that $\mathbf{u}_{\psi}=\nabla \psi$. Noticing the existence of ice divergence in reality, Moritz [1988] allows ice velocity to be represented by not only a stream function $\psi$ but also a velocity potential $\chi$, such that $\mathbf{u}=\mathbf{u}_{\psi}+\mathbf{u}_{\chi}$, with $\mathbf{u}_{\chi}=\nabla \chi$ containing the divergent part of the velocity field. Thus Moritz [1988] was able to derive the following correlation functions that are positive definite and allow ice divergence:

$$
\begin{aligned}
& B_{\|}(r)=\sigma^{2}\left[(1-v) \exp \left(-r_{1}^{2}\right)+v\left(1-2 r_{2}^{2}\right) \exp \left(-r_{2}^{2}\right)\right] \\
& B_{\perp}(r)=\sigma^{2}\left[(1-v)\left(1-2 r_{1}^{2}\right) \exp \left(-r_{1}^{2}\right)+v \exp \left(-r_{2}^{2}\right)\right]
\end{aligned}
$$

where $r_{1}=r / L_{\psi}, r_{2}=r / L_{\chi}, L_{\psi}$, and $L_{\chi}$ are correlation length scales for the ice velocity components corresponding, respectively, to the stream function and velocity potential $v=\sigma_{\chi}^{2} / \sigma^{2}$, and $\sigma_{\chi}^{2}$ is the error variance due to the divergent motions. Note that $v$ can be taken as the contributing factor of divergent motions to the total velocity error variance. For simplicity, we assume $L_{\psi}=L_{\chi}=L$.

[16] The correlation functions $\mathrm{B}_{\|}(r)$ and $\mathrm{B}_{\perp}(r)$ are estimated by conducting spatial correlation analysis on the differences between model-evaluated ice velocity and buoy velocity to determine $L$ and . Over 112,000 pairs of velocity differences (buoy velocities minus modeled velocities interpolated to the buoy points) during 1979-1993 were used for correlation analysis, which led to $L=736 \mathrm{~km}$ and $v=$ 0.27 as the best fit. The spatial distribution of the standard deviation of model velocity error, $\sigma=\sigma(x, y)$, is determined in the same way. It is location dependent and has a mean value of $0.068 \mathrm{~m} \mathrm{~s}^{-1}$ over the Arctic. The model error, together with $\sigma_{\text {bouy }}$ and $\sigma_{S S M / I}$ given in section 3.1, is used in equations (5), (8), and (9) for the OI assimilation procedure. During the procedure, a search of the observations in a range of $2000 \mathrm{~km}$ around each model grid cell is carried out, which allows a maximum of 5 buoy data and 10 $\mathrm{SSM} / \mathrm{I}$ data near the cell to be used for OI. This requires a solution of a matrix with up to 3030 elements for each grid cell when both buoy and SSM/I data are assimilated. The 
Table 1. Winter Comparisons of Model Velocities to Unassimilated Buoy Velocities $\left(\mathrm{m} \mathrm{s}^{-1}\right)$ With a Mean Speed of $0.075 \mathrm{~m} \mathrm{~s}^{-1}$ and a SD of $0.093 \mathrm{~m} \mathrm{~s}^{-1}$

\begin{tabular}{|c|c|c|c|c|c|c|}
\hline Case & $\begin{array}{l}\text { Number of } \\
\text { Buoy Data } \\
\text { Compared }\end{array}$ & $\begin{array}{l}\text { Mean } \\
\text { Model } \\
\text { Speed } \\
\end{array}$ & Bias & $\begin{array}{l}\text { SD of } \\
\text { Model } \\
\text { Motion }\end{array}$ & $\begin{array}{l}\text { Error } \\
\mathrm{SD} \\
\left(\sigma_{e}\right) \\
\end{array}$ & $\begin{array}{c}\text { Correlation } \\
(R) \\
\end{array}$ \\
\hline Model only & 12095 & 0.049 & -0.026 & 0.066 & 0.070 & 0.66 \\
\hline Model+ssmi & 12095 & 0.065 & -0.010 & 0.074 & 0.053 & 0.82 \\
\hline Model+buoy & 12095 & 0.072 & -0.003 & 0.087 & 0.044 & 0.88 \\
\hline Model+buoy+ssmi & 12095 & 0.068 & -0.007 & 0.081 & 0.041 & 0.90 \\
\hline Buoy data & & & & & 0.007 & \\
\hline $\mathrm{SSM} / \mathrm{I}$ data & & & & & 0.057 & \\
\hline
\end{tabular}

assimilation procedure is applied after the first guess ice motion is determined by solving the ice momentum equation. The assimilated ice motion is then used to solve equations (1), (2), and (3). The procedure increases the model run time by about one third. One-year integration on a HP C180 workstation consumes about 3 hours with no assimilation and 4 hours with assimilation.

[17] Note that the lateral boundary condition requires zero ice velocity at the model coast. Assimilation of ice motion data often fails to meet such a requirement, which is likely to cause artificial ice deformation at the coast. It is found that the spurious deformation at the coast causes excessive ice buildup in the TED model because of the ridging process. To avoid the spurious ice buildup, the OI-induced velocity component, the second term in equation (4), is linearly reduced from its full value at $240 \mathrm{~km}$ off the coast to zero at the coast. The value of $240 \mathrm{~km}$ is arbitrary, but the treatment is effective in eliminating the spurious ice buildup.

\section{Assimilation Results}

[18] In order to obtain insight into how assimilation of ice motion observations affects the ice velocity, deformation, and thickness simulated by a TED model, we examine 4 model runs with no assimilation or with different assimilation procedures. They are (1) Model only: model run without data assimilation; (2) Model+ssmi: model run with assimilation of SSM/I 2-day data only; (3) Model+buoy: model run with assimilation of daily buoy data only; and (4) Model+buoy+ssmi: model run with assimilation of daily buoy data and SSM/I 2-day data. These model runs were carried out for the period of 1992 to 1997 with the same initial conditions obtained by running the Model only case from 1979 to 1991.1992 is taken as a year of transition and the results for 1993 to 1997 are compared to the buoy motion data as well as the submarine ice thickness data.

\subsection{Ice Motion}

\subsubsection{Statistical Analyses}

[19] The efficacy of the different assimilation procedures can be evaluated by comparing the model velocity with the velocity of buoys that are not assimilated. Special assimilation runs were performed for the Model+buoy and Model+buoy+ssmi cases in which only odd numbered buoys were assimilated. Over the 5-year period, there were 19,861 velocity observations from odd numbered buoys used for assimilation and 18,605 from even numbered buoys used for comparisons. These two sets of buoys have the same mean speed of $0.080 \mathrm{~m} \mathrm{~s}^{-1}$ and velocity SD of $0.096 \mathrm{~m} \mathrm{~s}^{-1}$, indicating that their roles are interchangeable without changing the outcome of the comparisons. The even-numbered buoy data and the corresponding model velocities are compared over winter (defined as OctoberMay) when there are SSM/I data for assimilation and summer (defined as June-September) when there are not. Tables 1 and 2 show the winter and summer comparisons of the model velocities to the velocities of the unassimilated even-numbered buoys. Also included in Table 1 are the error SDs of buoy data and SSM/I data, $\sigma_{\text {bouy }}$ and $\sigma_{S S M / I}$.

[20] In winter, the velocity calculated by the Model only run has the highest bias, the highest error $\operatorname{SD}\left(\sigma_{\mathrm{e}}\right)$, and the lowest correlation $(R)$. Data assimilation significantly reduces the bias and error SD, and increases the correlation. The reduction in bias and error SD and the increase in correlation is most pronounced in the Model+buoy case. This is because the buoy motion error, $\sigma_{\text {bouy }}=0.007 \mathrm{~m} \mathrm{~s}^{-1}$, is considerably smaller than the modeled motion error, $\sigma_{\text {winter }}=$ $0.070 \mathrm{~m} \mathrm{~s}^{-1}$, which affords the buoys great leverage for improvement. However, the error SD $\left(0.044 \mathrm{~m} \mathrm{~s}^{-1}\right)$ in the Model+buoy case is still well above the buoy error. This is expected, since the assimilated ice velocity is a combination of model's first guess and statistically weighted observations as described in equation (4), and because the assimilated buoys are not collocated with the comparison buoys.

[21] Although assimilating only SSM/I data also significantly reduces model velocity bias and error $\mathrm{SD}$, the reduction is not expected to be as great as that made by assimilating buoy data. This is because the error SD of the $\mathrm{SSM} / \mathrm{I}$ motion is much closer to that of the model's first guess than the error SD of the buoy motion. The smaller difference between the error SDs of the SSM/I data and the model's first guess gives the SSM/I data a moderate weight in equation (4). The question is: why not allow SSM/I data to be more strongly weighted in the OI assimilation procedure so as to magnify their influence in the model? As mentioned in section 3.1, artificially reducing the error SD for SSM/I observations in equation (5) and therefore increasing their weights in equation (4) does not improve the model results. On the other hand, the statistical tests do not operate where there are SSM/I data but no buoy data. Therefore the improvement made by SSM/I data may be underestimated, given that SSM/I data have a much better area coverage in the Arctic than buoy data. Because of their better coverage, assimilating SSM/I data in addition to buoy data (Model+buoy+ssmi) further improves the calculation

Table 2. Summer Comparisons of Model Velocities to Unassimilated Buoy Velocities $\left(\mathrm{m} \mathrm{s}^{-1}\right)$ With a Mean Speed of $0.087 \mathrm{~m} \mathrm{~s}^{-1}$ and a SD of $0.102 \mathrm{~m} \mathrm{~s}^{-1 \mathrm{a}}$

\begin{tabular}{lccccccc}
\hline & $\begin{array}{c}\text { Number of Mean } \\
\text { Buoy Data Model } \\
\text { Case }\end{array}$ & $\begin{array}{c}\text { SD of } \\
\text { Compared }\end{array}$ & Speed & Bias & $\begin{array}{c}\text { Error } \\
\text { Motion }\end{array}$ & $\begin{array}{c}\text { SD } \\
\left(\sigma_{e}\right)\end{array}$ & $\begin{array}{c}\text { Correlation } \\
(R)\end{array}$ \\
\hline Model only & 6510 & 0.073 & -0.014 & 0.088 & 0.070 & 0.74 \\
Model+ssmi & 6510 & 0.076 & -0.011 & 0.090 & 0.070 & 0.74 \\
Model+buoy & 6510 & 0.085 & -0.002 & 0.100 & 0.056 & 0.85 \\
Model+buoy+ssmi & 6510 & 0.085 & -0.002 & 0.099 & 0.056 & 0.85 \\
\hline
\end{tabular}

${ }^{a}$ No summer SSM/I motion data are assimilated. 


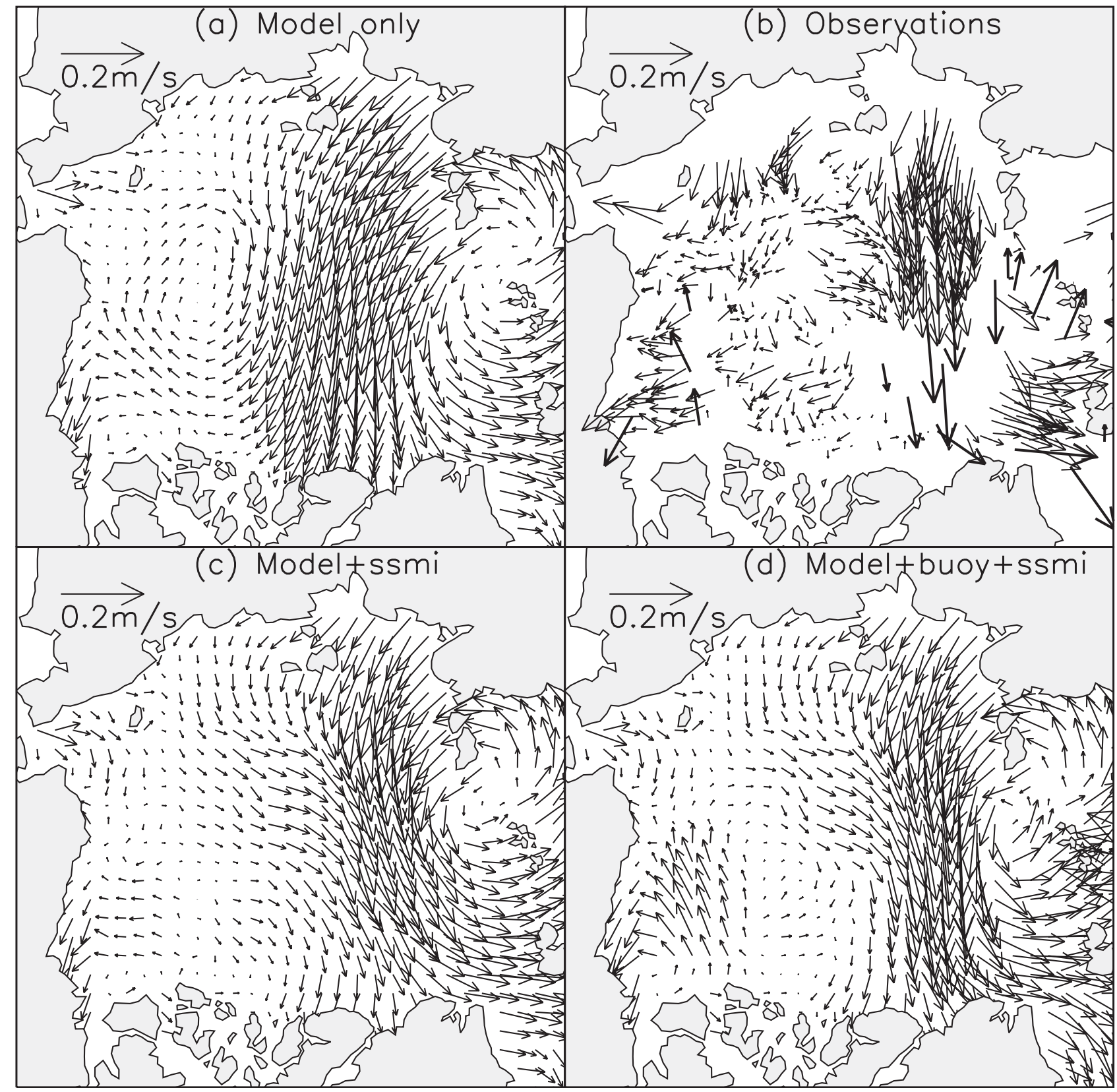

Figure 2. Ice velocity fields for January 1, 1993, modeled by (a) the Model only run, (c) the Model+ssmi run, and (d) the Model+buoy+ssmi run; one vector is drawn for every 9 grid cells. (b) Buoy velocities (thick vectors) and SSM/I ice velocities (thin vectors) assimilated for January 1, 1993.

of ice motion, achieving the best overall performance in comparison with the unassimilated buoys.

[22] In summer the velocities calculated by the Model only case compare better statistically with the velocities of the even numbered buoys with a reduced bias and increased correlation (Table 2). Why does the Model only case behave better in summer than in winter? The answer to this question is elusive. To speculate, it could be that the air drag or water drag is more realistic for summer, or that the ice strength parameterization is less realistic for winter when ice is thick and strong, or that the model simply better handles the summer conditions of thinner ice and free drift. Since there are no SSM/I data in summer, there is no improvement from assimilating only SSM/I data. Assimilating buoy data still improves the model behavior in summer, but to a lesser degree: The error SD of the Model+buoy case in summer does not decrease as much as in winter. This may be attributed to two factors: the Model only run performs better in summer, and both buoy and model velocities have higher summer mean speed and SD. The ratio of error SD and buoy velocity SD in summer is close to that in winter.

\subsubsection{Velocity Fields and Distributions}

[23] From here on, the results for the Model+buoy and Model+buoy+ssmi assimilation runs include all the buoys, both odd and even numbered. Figure 2 shows an example of how assimilation influences the modeled ice velocity for the 
first day of 1993. Figure $2 \mathrm{a}$ is the velocity field simulated by the model run without assimilation. Figure $2 b$ shows the buoy and SSM/I velocity vectors assimilated for that day. Some of the SSM/I vectors are aligned with the buoy vectors, some are not, which reflects the sizable uncertainty of the SSM/I data. The velocity pattern is substantially changed by data assimilation in most of the Arctic Basin (Figures 2c and 2d). In the central Arctic the modeled velocities are steered toward Fram Strait by the $\mathrm{SSM} / \mathrm{I}$ and buoy observations. The influence of the buoy data appears most noticable in the Beaufort Sea, in Fram Strait, and near Franz Josef Land (Figures 2c and 2d). This is attributed to the fact that the buoy motion error is about one order of magnitude smaller than the model velocity error, which allows buoy data to be heavily weighted in equation (4).

[24] The cumulative effect of assimilation on the spatial distribution of ice velocity over 1993-1997 is shown in Figure 3. The assimilation accelerates ice in most of the Arctic regions, including specifically the East Siberian, Laptev, Kara, Beaufort, and Greenland seas. The anticyclonic ice circulation is more confined to the Beaufort Sea, which is in line with the climatological buoy motion field [Rigor et al., 2002]. The transpolar ice stream is stronger and is better aligned with the climatological transpolar buoy drift [Rigor et al., 2002]. As shown in Figures 3d and 3e, the influence of SSM/I data on the ice velocity field is similar to that of buoy data in the Beaufort Sea and is different from that of buoy data in the East Siberian Sea and near Fram Strait. The velocity field from the Model+buoy+ssmi run (Figure 3f) looks more like that from the Model+buoy run than that from the Model+ssmi run. This indicates that, when a combination of SSM/I and buoy data is assimilated, the effect of SSM/I data is moderate and the effect of buoy data is strong. Perhaps the most notable difference between the velocities calculated by the Model + sssmi case and the Model+buoy+ssmi case or the Model+buoy case lies in the strength of the transpolar ice stream and the ice outflow at Fram Strait. Assimilating buoy data induces even larger ice speed at Fram Strait where buoys often speedily exit the Arctic and the satellite remote sensing may not be very effective in tracking the ice moving particularly fast in that area.

[25] Figure 4a compares the distributions of the buoy drift speeds and the simulated ice speeds at the buoy locations. A conspicuous feature is the Model only case's substantial overestimate of ice stoppage (see the large peak for zero speed), indicating that the ice dynamic component of the model needs further improvement. Assimilation reduces the stoppage rather successfully. It also improves the estimate of ice moving with a speed larger than $0.04 \mathrm{~m} \mathrm{~s}^{-1}$. The speed distribution from the Model + ssmi case is very close to that from the Model+buoy case, indicating that SSM/I data are very effective in improving the ice velocities at the buoy locations. Furthermore, the distribution from the Model+buoy+ssmi run has the best match with that from the buoy observations over the whole speed range, indicating that the SSM/I data's better area coverage further contributes to the improvement of the simulated ice motion.

[26] In fact, the effect of SSM/I data is more noticable in Figure $4 \mathrm{~b}$, which shows the simulated ice speed distribution over the Chukchi, East Siberian, and Laptev seas, where few buoys were deployed. Assimilating SSM/I observations, with their large area coverage, reduces the stoppage in the shelf regions more substantially than assimilating only buoy observations, observations that are often distant from the shelves.

\subsection{Ice Outflow}

[27] Figure 5a shows the simulated annual mean ice areal outflow at Fram Strait. Also included in the figure is the areal outflow estimated by Kwok and Rothrock [1999] using SSM/I data acquired from both $85 \mathrm{Ghz}$ and $37 \mathrm{Ghz}$ channels. To varying degrees, assimilation elevates the ice areal outflow owing to its strengthening of the transpolar ice stream. Not surprisingly, the results from the Model+ssmi run best match the estimates by Kwok and Rothrock [1999] (see also Table 3). The increase in ice areal outflow resulting from assimilating only $\mathrm{SSM} / \mathrm{I}$ data is generally smaller than the increase resulting from assimilating buoy data, which is in agreement with Figure 3, which shows that buoy data give even larger ice speeds at Fram Strait. The ice areal outflow with assimilated buoy data is increased substantially in 1993 and 1994, but is suppressed a little by additionally assimilating SSM/I data. The huge increase in areal outflow in these two years may be linked to a large number of fast-moving buoys (Figure 5b) in the Fram Strait area. This suggests the need for more continual and accurate velocity observations in Fram Strait.

[28] Figure 5b shows the simulated annual mean ice volume outflow at Fram Strait and the estimates from Vinje et al. [1998] using ice draft observations from moored sonars. Again, assimilation increases ice volume outflow, corresponding to the increase in ice areal outflow at Fram Strait. While it brings the simulated areal outflow closer to the estimate of Kwok and Rothrock [1999] for 1993, it causes a large increase in volume outflow over the estimate by Vinje et al. The assimilation-enhanced ice volume outflow is in a better agreement with Vinje et al. for 1994. Assimilation does not change the volume outflow for 1995; all the model runs generate more outflow than the estimate of Vinje et al., a possible bias caused by either model forcing or model physics. Over the 1993-1995 period covered by the estimates of Vinje et al., the modeled volume outflow is about $13-27 \%$ larger than the estimates (Table 3 ), which may be partially due to data assimilation, partially due to errors in the model forcing or physics, and possibly due to observation errors.

\subsection{Ice Deformation}

[29] How does assimilation impact the modeling of ice deformation? Given that it increases ice speed and reduces ice stoppage, we expect an increased ice deformation rate. Figure 6 shows the simulated fields of ice deformation rate for the first day of 1993. Here deformation rate (simply called deformation hereinafter) is defined as $\sqrt{\left(\dot{\varepsilon}_{11}+\dot{\varepsilon}_{22}\right)^{2}+\left(\dot{\varepsilon}_{11}-\dot{\varepsilon}_{22}\right)^{2}+4 \dot{\varepsilon}_{12}^{2}}$, where $\dot{\varepsilon}_{i j}$ is the second order strain rate tensor. The ice deformation simulated by all four cases is generally within the range of $0-10 \% \mathrm{~d}^{-1}$. Deformation is significantly increased by assimilating either SSM/I data or buoy data. For the selected day, the deformation calculated by the Model+ssmi and Model+buoy+ssmi cases is smaller than that calculated by the Model+buoy case in some areas, such as the Eurasian Basin and Fram Strait, where there are 


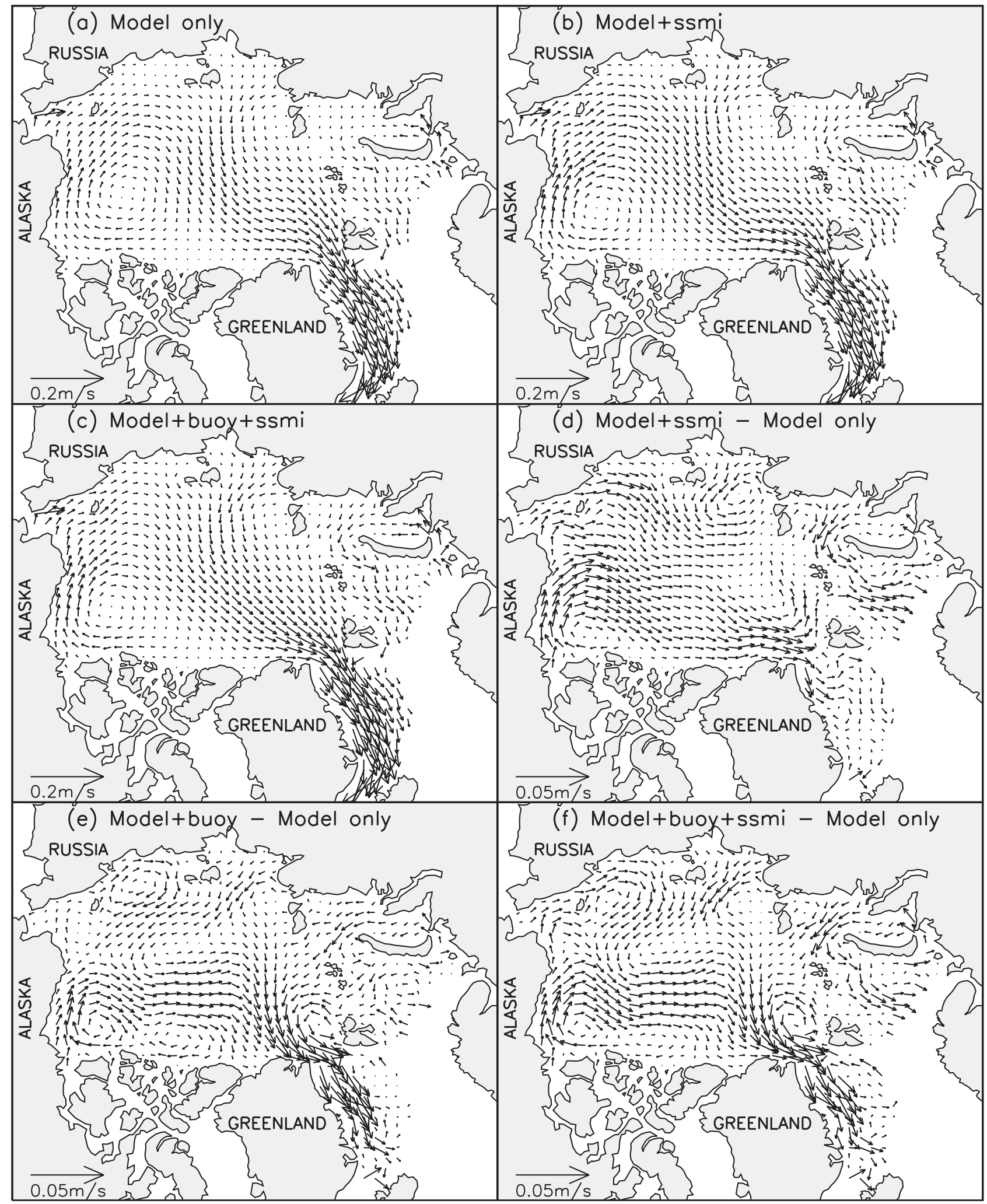

Figure 3. The 1993-1997 mean ice velocity fields for (a) the Model only run, (b) the Model+ssmi run, and (c) the Model+buoy+ssmi run. The 1993-1997 mean ice velocity differences (d) between the Model+ssmi and Model only cases, (e) between the Model+buoy and Model only cases, and (f) between the Model+buoy+ssmi and Model only cases. One vector is drawn for every nine grid cells. Note the different vector scales in different panels. 


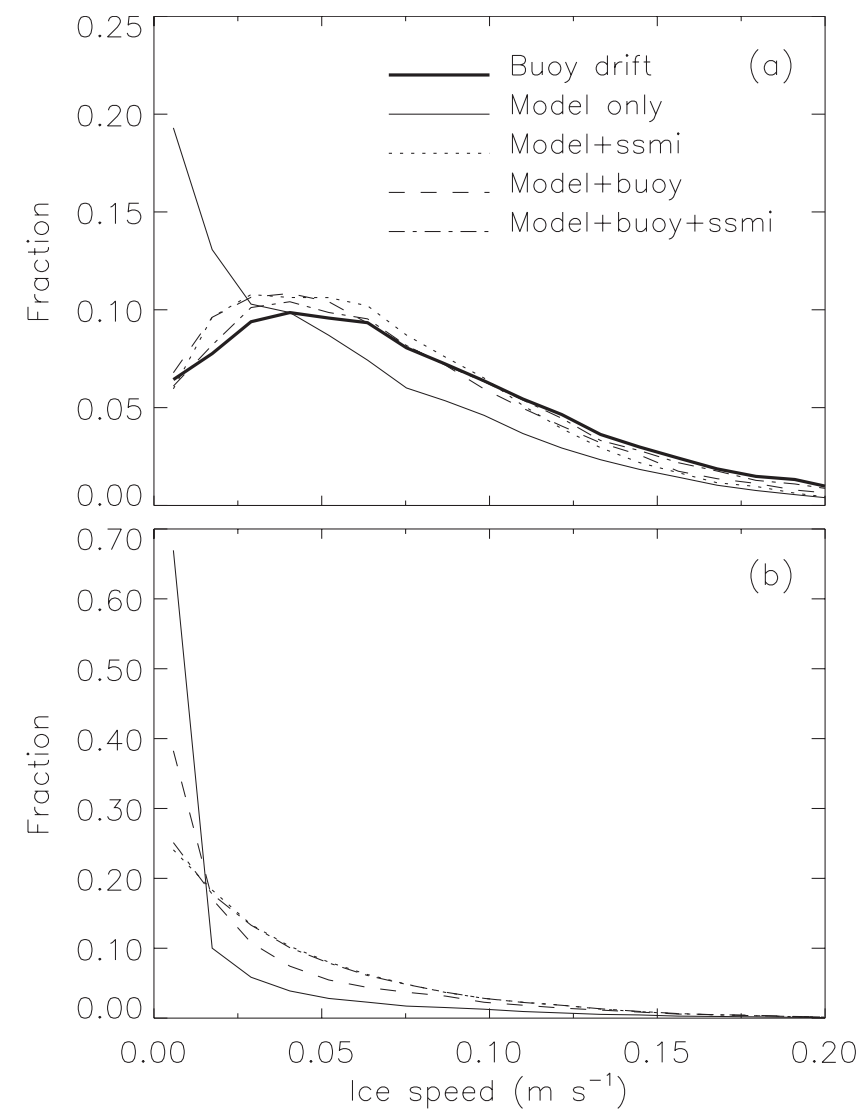

Figure 4. (a) Distributions of simulated ice speed and observed Arctic buoy drift speed, based on all the available daily buoy drift data for the Arctic from 1993 to 1997 and simulated daily mean ice velocities corresponding to the times and locations of buoy data. (b) Distributions of simulated ice speed for the Chukchi, East Siberian, and Laptev seas from 1993 to 1997.

quite a few buoys (Figure 2). This illustrates the role of moderation the SSM/I observations often play when jointly assimilated with buoy data.

[30] However, SSM/I data do not seem to play a role of moderation in shaping ice deformation over a longer timescale, as seen in the fields of averaged ice deformation (Figure 7). Quite the contrary, SSM/I data increase ice deformation almost everywhere in the Arctic than buoy data do. One possible reason is that the SSM/I data have a wider spatial coverage than the buoy data, which consistently cause a larger ice deformation in areas where buoys' influence is sporadic, particularly in the shelf regions.

[31] Figure 8 shows deformation distributions for the entire Arctic Basin during 1993-1997. As can be seen, the Model only run creates the highest percentage of low deformation $\left(<1 \% \mathrm{~d}^{-1}\right)$, in line with its excessive ice stoppage (Figure 4). Assimilation significantly reduces the percentage of low deformation and increases the deformation over a wide range of larger values. The SSM/I data are more effective in reducing the percentage of low deformation and in increasing the percentage of higher deformation than the buoy data, in line with the fields of deformation shown in Figure 7.
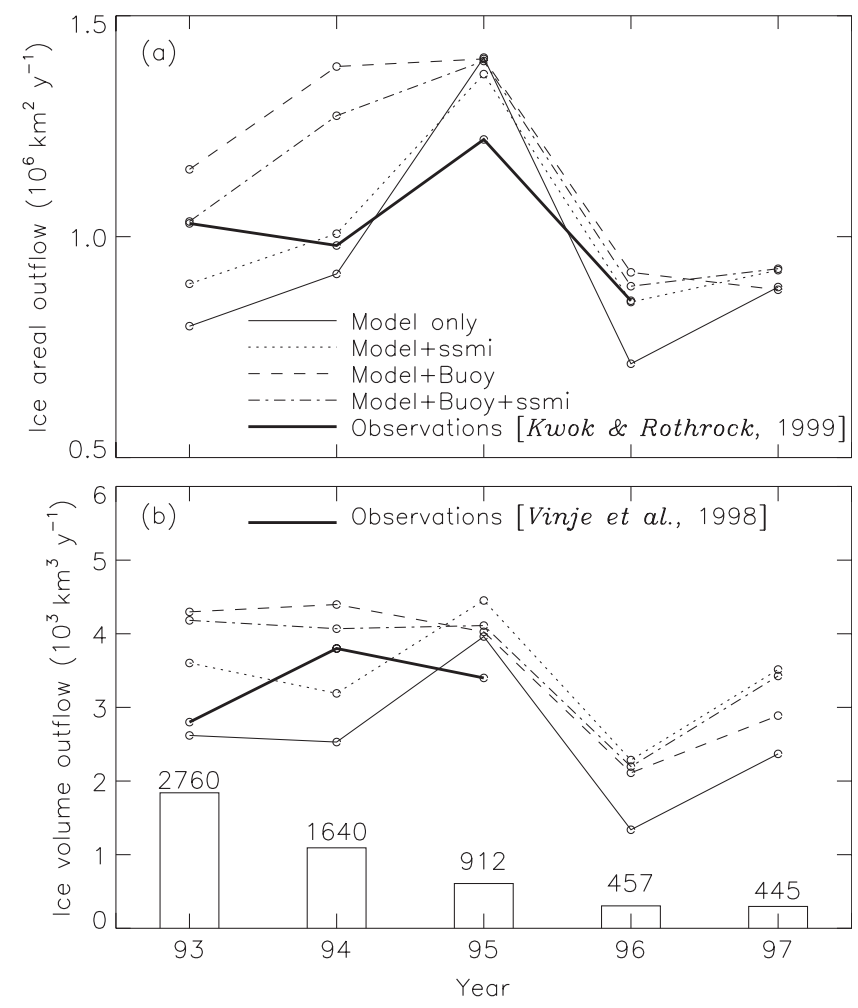

Figure 5. Annual mean ice outflows of (a) area and (b) volume at Fram Strait. Also included are the estimate of ice areal outflow in Figure 5a by Kwok and Rothrock [1999] using SSM/I ice motion data, and the estimate in Figure 5b by Vinje et al. [1998] using ice draft data from moored sonars. The histograms in Figure $5 \mathrm{~b}$ show the annual number of buoy motion data in the Fram Strait area.

[32] Lindsay et al. [2003] compare the ice deformation rate from these same series of simulations to highly accurate observations of the deformation rate provided by the RadarSat Geophysical Processor System (RGPS [see Kwok, 1998]). The RGPS follows thousands of locations in satellite synthetic aperture radar images. The spatial separation of the points is roughly $10 \mathrm{~km}$ and the temporal sampling is typically 3 days. A 10-month period starting in the fall 1997 was analyzed. The correlation of the total deformation, estimated for a spatial scale of $320 \mathrm{~km}$, between the Model only run and the observations is very low at all locations in both winter and summer. However, the correlation between

Table 3. Observed Mean Ice Areal Outflow $\left(10^{6} \mathrm{~km}^{2} \mathrm{yr}^{-1}\right)$ From Kwok and Rothrock [1999], Observed Mean Ice Volume Outflow $\left(10^{3} \mathrm{~km}^{3} \mathrm{yr}^{-1}\right)$ From Vinje et al. [1998], and Simulated Mean Ice Areal and Volume Outflows, All at Fram Strait ${ }^{\mathrm{a}}$

\begin{tabular}{lcc}
\hline \multicolumn{1}{c}{ Case } & $\begin{array}{c}\text { Areal Outflow } \\
(1993-1996)\end{array}$ & $\begin{array}{c}\text { Volume Outflow } \\
(1993-1995)\end{array}$ \\
\hline Kwok and Rothrock [1999] & $1.02(-)$ & \\
Vinje et al. $[1998]$ & & $3.33(-)$ \\
Model only & $0.96(0.94)$ & $3.04(2.56)$ \\
Model+ssmi & $1.03(1.01)$ & $3.75(3.41)$ \\
Model+buoy & $1.21(1.15)$ & $4.24(3.54)$ \\
Model+buoy+ssmi & $1.15(1.10)$ & $4.12(3.60)$ \\
\hline
\end{tabular}

${ }^{a}$ Numbers in parentheses are 1993-1997 mean. 


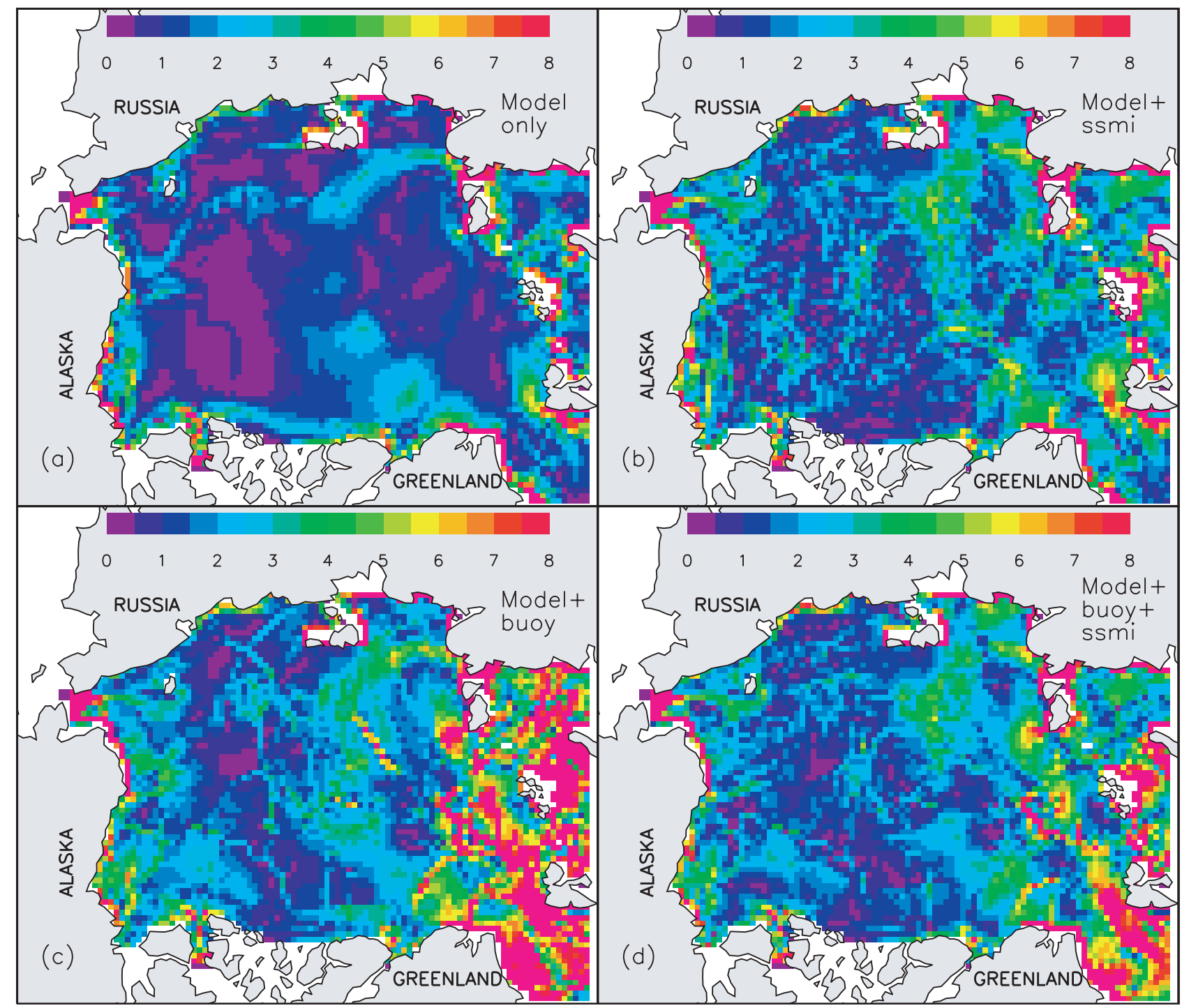

Figure 6. Modeled ice deformation $\left(\% \mathrm{~d}^{-1}\right)$ for January 1, 1993.

the Model+buoy+ssmi run and the observations is high in the winter far from the coasts (maximum $R=0.87$ ). In the summer it is generally quite low except in regions where many buoys were available for assimilation.

\subsection{Ice Thickness}

\subsubsection{Influence on Ice Ridging}

[33] Figures 6, 7, and 8 show that assimilating ice motion observations considerably enhances ice deformation. It is therefore no surprise that assimilation increases ridged ice production (Figure 9). (There are no negative values in the difference fields in Figure 9.) The buoy-induced increase in ridged ice production is particularly large near the Canadian Archipelago and the North Greenland coast where it is somewhat subdued by additionally assimilating SSM/I data (Figures $9 \mathrm{~b}$ and 9c). The SSM/I-induced increase is small near the coast of Alaska and relatively large in the East Siberian and Laptev seas because of a stronger ice motion in the shelf regions shown in Figure 4b. Although their spatial distributions of ridged ice production are strikingly different (Figure 9), any of the three assimilation runs roughly doubles the basin-wide mean annual ridged ice production (Table 4).

[34] Five annual cycles of the ridged ice thickness as well as the undeformed and total (ridged plus undeformed) ice thicknesses are illustrated in Figure 10. By ridged ice thickness we mean ridged ice volume per unit area, and similarly for undeformed ice thickness. Without data assimilation, the model estimates a mean ridged ice thickness well under $1 \mathrm{~m}$ and a mean undeformed ice thickness close to 2 $\mathrm{m}$; ridged ice is about one quarter of the total. Data assimilation decreases the amount of undeformed ice, increases the ridged ice, and brings the ridged ice up to about half of the total.

[35] What explains the increased amplitude of the seasonal cycle of total ice thickness (Figure 10c, Table 4) when buoy or SSM/I data are assimilated? In winter, more deformation converts more undeformed ice to ridged ice. At the same time, it produces more open water in which most of the undeformed ice lost to ridging is replenished. Thus there is more production that raises the winter maximum. Ridged ice tends to melt more rapidly in summer 


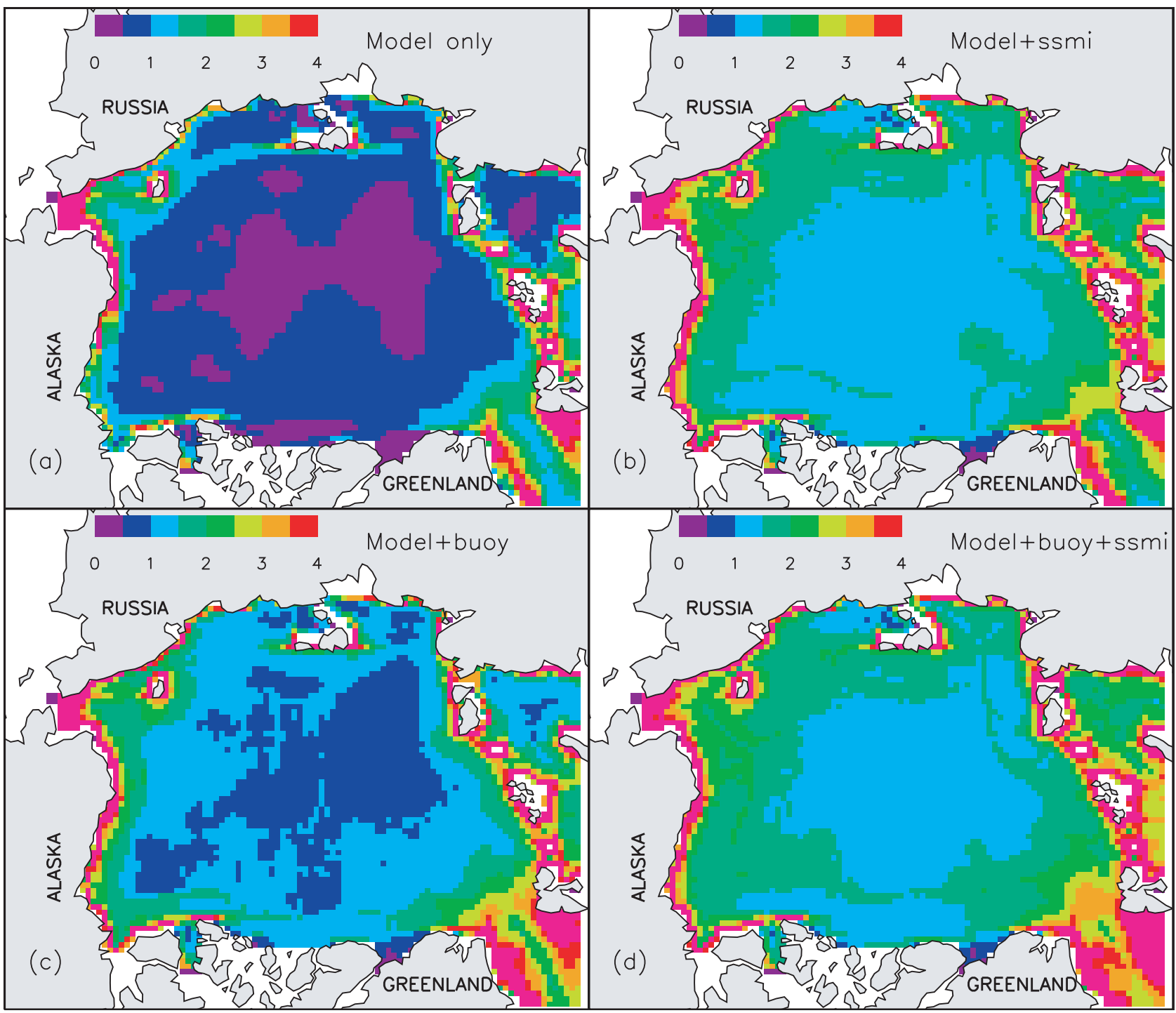

Figure 7. Modeled ice deformation $\left(\% \mathrm{~d}^{-1}\right)$ averaged over 1993-1997.

because of its greater areal contact with warmed surface water, which, together with the increased outflow owing to assimilation (Figure 5), removes the excess ice produced during the winter, and leaves the annual minimum largely unaffected by assimilation.

[36] Figure 11 compares the simulated mean ice thickness fields. The pattern of the thickness field simulated by the Model+buoy+ssmi (Figure 11a) agrees reasonably well with that observed by Bourke and McLaren [1992]. This is a pattern of thicker ice off the Canadian Archipelago and North Greenland coast and thinner ice in the eastern Arctic. Compared to the Model only case, assimilating buoy data makes the thicker ice even thicker, owing to an increased production of ridged ice in the western Arctic, and the thinner ice even thinner, owing to a stronger transpolar ice stream and outflow (Figure 11c). In other words, the effect of assimilating buoy data is to reduce ice in the eastern Arctic and increase ice in the western Arctic. This is not so, however, with the Model+ssmi run (Figure 11b). The influence of SSM/I data is to increase ice in the areas near the Canadian Archipelago, the coast of North Greenland, Fram Strait, and Franz Josef Land, and to reduce ice near the coast of Alaska and in the Chukchi and East Siberian seas. The striking difference in ice thickness between the Model+buoy and Model+ssmi runs is apparently linked to the spatial pattern of ridged ice production, although they

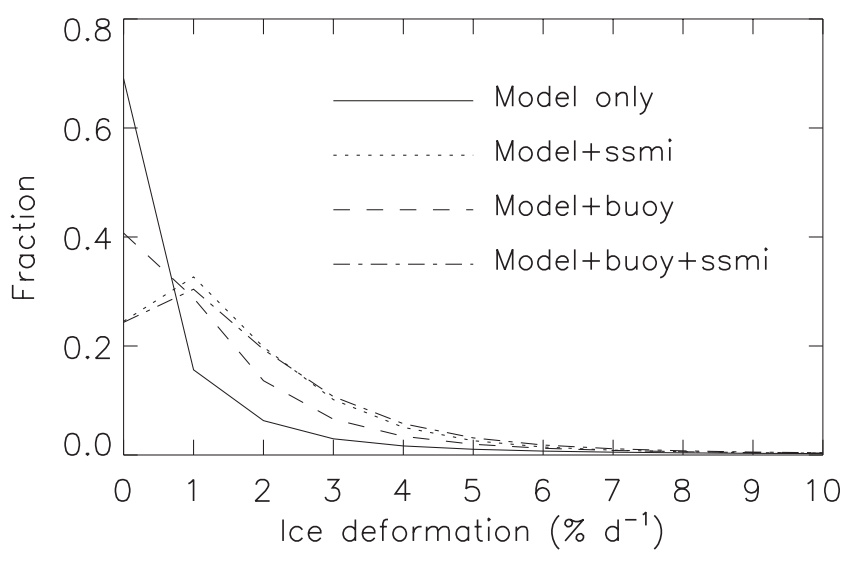

Figure 8. Distributions of modeled ice deformation calculated over the Arctic Basin during 1993-1997. 


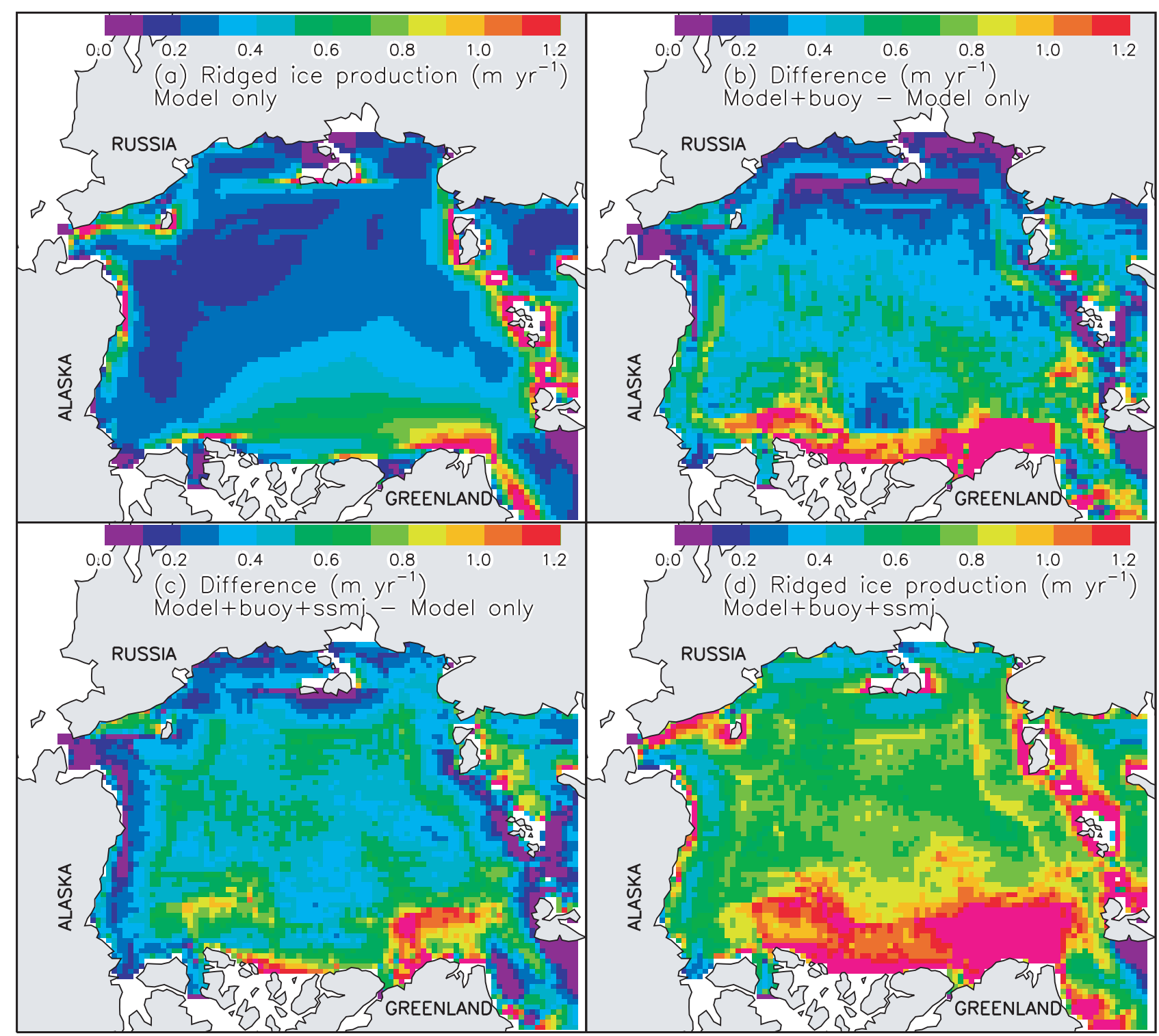

Figure 9. Mean (a, d) ridged ice production fields and (b, c) difference fields, all for 1993-1997.

remain close in basin-wide averages of ridged ice production, ridged ice volume, and total ice volume. The difference field in Figure 11d reflects the influence of both SSM/I data and buoy data.

\subsubsection{Comparisons With Submarine} Ice Thickness Data

[37] The results presented so far have shown that assimilating the ice motion data, particularly buoy data, leads to greater ice outflow at Fram Strait. It also leads to a larger ice deformation, which in turn results in increased production of ridged ice. All of this ultimately influences the simulation of ice thickness. Is the influence detrimental to or helpful in reducing the error of modeled ice thickness, and to what extent? To address this question, we compare the simulated ice thickness results with submarine observations of ice thickness.

[38] The submarine ice thickness data are provided by the National Snow and Ice Data Center. The data were acquired by four submarine cruises during 1993-1997. The available data along the tracks of the cruises are marked in Figure 12,

Table 4. Ridged Ice Production (in $\mathrm{m} \mathrm{yr}^{-1}$ ) and Ice Thickness (m) Averaged Over the Whole Arctic Basin for $1993-1997$

\begin{tabular}{lccccc}
\hline \multicolumn{1}{c}{ Case } & $\begin{array}{c}\text { Ridged Ice } \\
\text { Production }\end{array}$ & $\begin{array}{c}\text { Ridged Ice } \\
\text { Thickness }\end{array}$ & $\begin{array}{c}\text { Undeformed Ice } \\
\text { Thickness }\end{array}$ & $\begin{array}{c}\text { Total Ice } \\
\text { Thickness }\end{array}$ & $\begin{array}{c}\text { Seasonal Range of } \\
\text { Total Ice Thickness }\end{array}$ \\
\hline Model only & 0.35 & 0.64 & 1.78 & 2.42 & 0.88 \\
Model+ssmi & 0.73 & 1.22 & 1.29 & 2.51 & 1.07 \\
Model+buoy & 0.79 & 1.29 & 1.30 & 2.59 & 1.13 \\
Model+buoy+ssmi & 0.77 & 1.25 & 1.33 & 2.58 & 1.11 \\
\hline
\end{tabular}




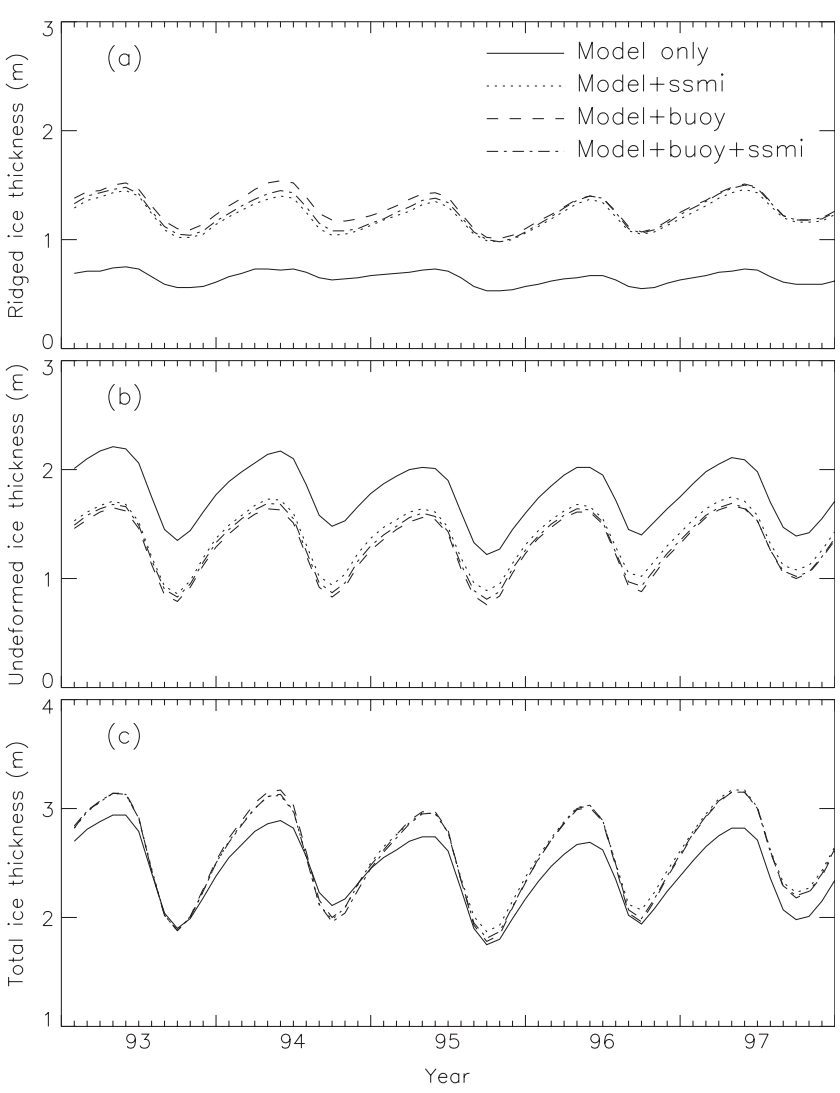

Figure 10. Monthly mean thicknesses of (a) ridged ice, (b) undeformed ice, and (c) total (ridged plus undeformed) ice.

where each circle represents a datum of ice thickness averaged over a distance of $\sim 10-50 \mathrm{~km}$ along the tracks. For comparisons, we sampled the modeled ice thickness at the location of each circle at the corresponding time. The modeled ice thickness estimates were from $40 \mathrm{~km} \times 40 \mathrm{~km}$ grid cells, whereas the submarine data were collected along a line.

[39] Figure 13 compares the modeled and observed ice thicknesses along the four submarine tracks. Among all the cases, the Model only case is least likely to capture the observed variability of ice thickness along these tracks. On the other hand, assimilating buoy data tends to occasionally cause extreme ice thicknesses, such as those near location $F$ (see Figure 12), in between $\mathrm{G}$ and $\mathrm{H}$, and after $\mathrm{H}$, as shown in Figure $13 \mathrm{c}$. These thickness extrema indicate that the buoy-induced ice deformation may be excessive in those locations. The buoy-induced extrema are somewhat suppressed by additionally assimilating $\mathrm{SSM} / \mathrm{I}$ data (Figure 13d). Assimilating both SSM/I and buoy data significantly improves ice thickness in the Beaufort Sea in 1996 (around G).

[40] Table 5 and Figure 14 provide an overall assessment by comparing the modeled and observed thicknesses along all four cruise tracks combined. Overall, the biases for the four model runs are all within a range of $0.26 \mathrm{~m}$. Of all the runs, the case without data assimilation has the lowest spatial variability $(\mathrm{SD}=0.50)$ in ice thickness and lowest model-data correlation $(\mathrm{R}=0.45)$, which is also reflected in Figure 14a. Assimilating only SSM/I motion data slightly raises the correlation and substantially increases the spatial variability $(\mathrm{SD}=0.81)$ to a level close to that of submarine observations $(\mathrm{SD}=0.84)$. This is also reflected in Figure $14 \mathrm{~b}$ that shows more points spreading vertically than Figure 14a, but the Model+ssmi run also increases bias and error SD over the Model only run. Hence assimilating only SSM/I motion data does not necessarily improve the error statistics of the simulated ice thickness along the four submarine tracks.

[41] The buoy-induced spatial variability $(\mathrm{SD}=0.83)$ is close to the SSM/I-induced one, but the Model+buoy run further increases the correlation over the Model only run. The error SD of the Model+buoy run manages to be close to that of the Model only case, even though the former has a much greater SD than the latter. Assimilating both SSM/I and buoy data achieves the best overall performance with highest correlation and lowest error SD (also see Figure 14d). This is because buoy data often improve the model simulation of ice thickness where SSM/I data do not, and vice versa (Figure 13). Also, SSM/I data tend to suppress the extreme thicknesses caused by buoy data alone. This reveals the complementary roles that SSM/I data and buoy data play in improving the simulation of ice thickness.

\section{Concluding Remarks}

[42] Large-scale sea-ice models have been improved in recent years by incorporating more realistic ice dynamics and thermodynamics. However, there are still many uncertainties inherent in the forcing fields and in the model components, resulting in errors in the transfer of heat, mass, and momentum at the ice surface and bottom, and in the ice albedo, ice strength, and ice ridging. Consequently, model hindcasts of Arctic sea ice often deviate from reality. Model errors may be reduced by assimilating observations to draw the models toward reality. This paper investigates the effects of assimilating ice motion data from buoys and satellite imagery into a TED sea-ice model.

[43] The major issues about data assimilation are choosing an assimilation scheme (optimal interpolation in our case), knowing the error magnitude in the model and in the data to be assimilated, and assessing the reduction in modeling errors as a result of assimilation. The buoy data are especially useful for constraining the model because they have a measurement error $\left(0.007 \mathrm{~m} \mathrm{~s}^{-1}\right)$ an order of magnitude smaller than modeled ice motion error $(0.070 \mathrm{~m}$ $\mathrm{s}^{-1}$ ). Assimilating buoy data substantially reduces the bias and error SD of the modeled motions (Tables 1 and 2). The $\mathrm{SSM} / \mathrm{I}$ ice velocities are also useful for data assimilation because their errors $\left(0.058 \mathrm{~m} \mathrm{~s}^{-1}\right)$, although larger than buoy errors, are still smaller than modeling errors, and because SSM/I data provide more complete coverage than buoys and improve model behavior where buoy coverage is sparse, such as in the marginal seas. SSM/I data are not available during the summer melt. The SSM/I two-day data were chosen for data assimilation because they yield better model results when compared with buoy drift data and submarine ice thickness data. How big a role SSM/I data play in an optimal interpolation assimilation procedure is linked to their error variance. Changing their influence by artificially varying their error variance does not improve the model results. 


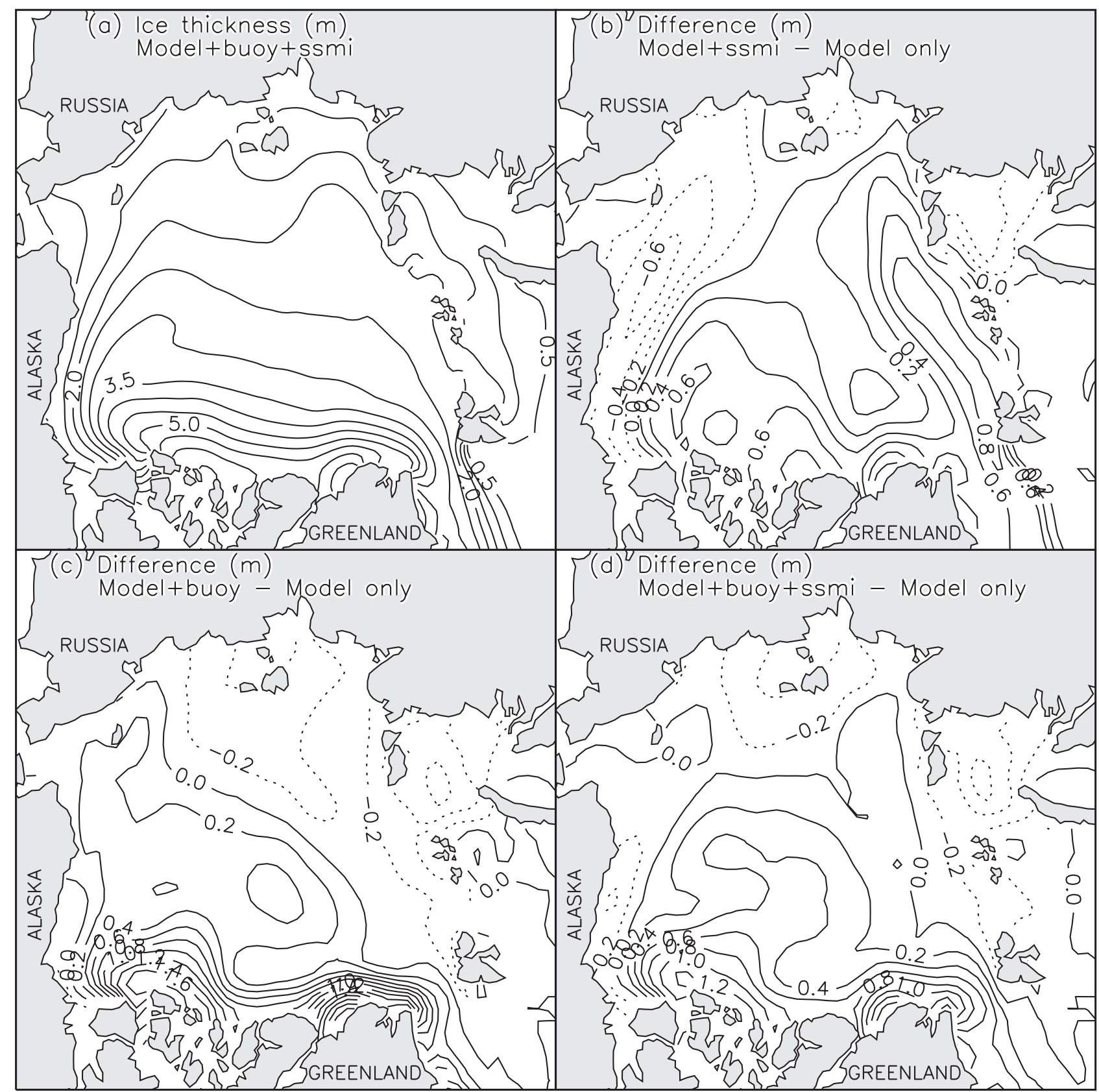

Figure 11. Mean (a) ice thickness and (b, c, d) difference fields, all for 1993-1997.

[44] What does assimilation change and, in particular, what does it improve? Without data assimilation, the modeled ice motion is sluggish with excessive stoppage. Assimilating motions leads to strengthened ice motion and deformation and to substantially reduced stoppage. The distribution of ice speed becomes much more like that of observations (Figure 4a). Assimilation also leads to strengthened ice outflow through Fram Strait. The error $\mathrm{SD}$ of the modeled velocity, which is $0.070 \mathrm{~m} \mathrm{~s}^{-1}$ without assimilation, drops with assimilation to $0.041 \mathrm{~m} \mathrm{~s}^{-1}$ in winter and $0.056 \mathrm{~m} \mathrm{~s}^{-1}$ in summer (Tables 1 and 2).

[45] The strengthened ice motion and deformation that come with assimilation have major effects on ice thickness. Assimilation produces more ridged ice, and more total ice, and displays a greater seasonal amplitude of thickness. However, in all three data assimilation runs, the ridged ice production, ridged ice volume, and total ice volume averaged over the whole Arctic are similar. More significantly, the spatial pattern of ice thickness is modified. When both buoy- and satellite-derived motions are assimilated, the ice along the Canadian archipelago from Banks Island to northeast Greenland is thicker by about one meter. Ice in the central Arctic Ocean becomes a couple tens of centimeters thicker, and ice in the marginal seas becomes a couple tens of centimeters thinner. The satellite data provide the thinning influence in the southern Beaufort, Chukchi, and East Siberian seas; the buoys provide the thinning influence in the eastern marginal seas, and both provide a thickening influence elsewhere. When compared with ice thickness observed from sub- 


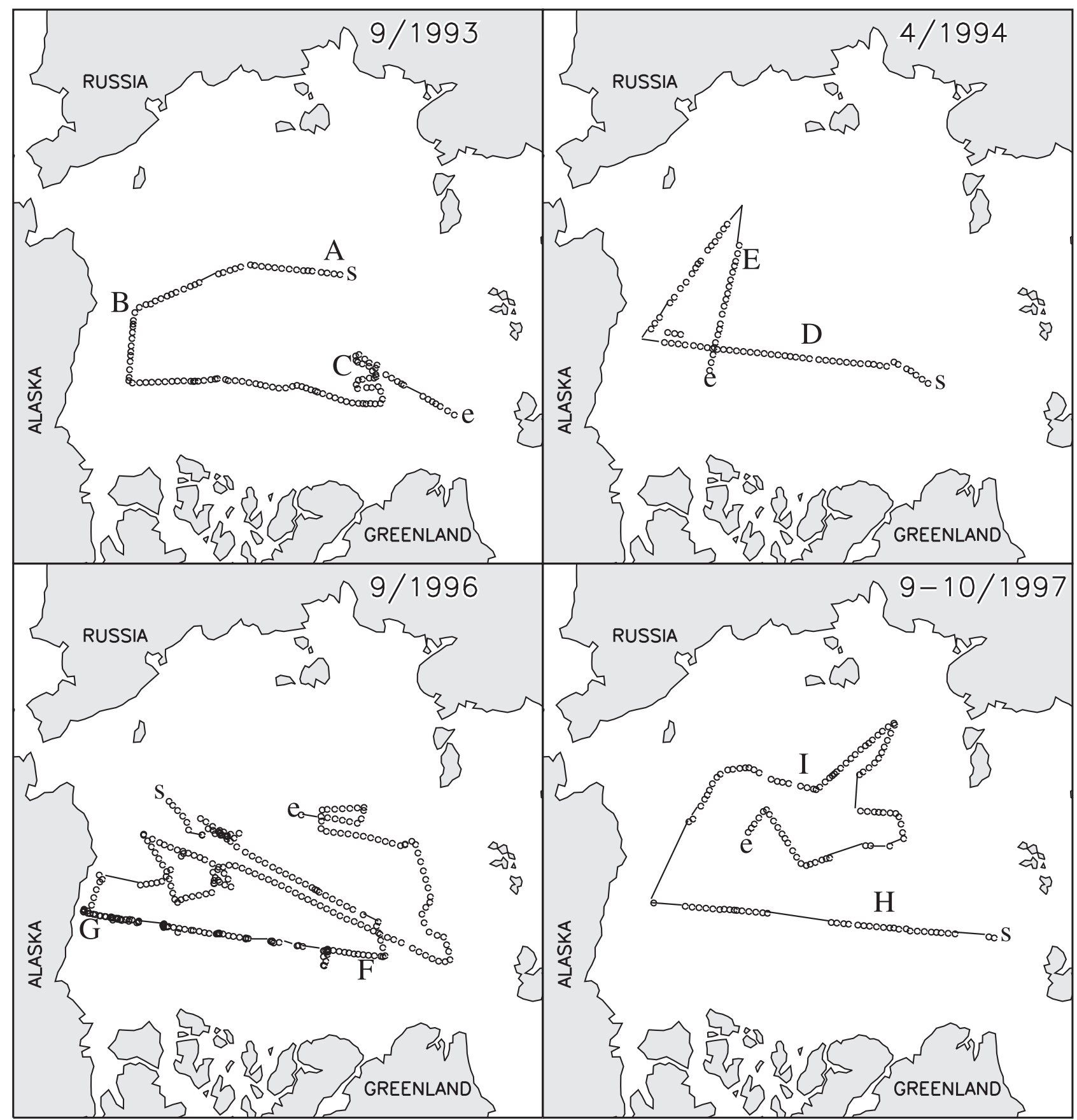

Figure 12. Available submarine observations of ice thickness collected along four tracks of submarine cruises in September 1993, April 1994, September 1996, and September-October 1997. Each circle in the plot represents a record of ice thickness averaged over a distance of $\sim 10-50 \mathrm{~km}$ along the tracks. Solid lines represent approximate submarine paths where ice thickness data are not available. The lowercase letters indicate the start (s) and end (e) of each track. The uppercase letters are marked for analyzing the results.

marines, the model is brought slightly closer to thickness data by assimilation. Without assimilation the correlation between the model and observations is 0.45 ; assimilation raises the correlation to 0.65 . The standard deviation of the error is reduced from $0.76 \mathrm{~m}$ without assimilation to $0.66 \mathrm{~m}$ with it (Table 5).

[46] What does assimilation tell us about likely sources of error in our models? We find that assimilating ice motion data tends to strengthen spatial gradients of velocity. This is an indication that the wind fields used to force models lack spatial resolution. Small, intense features such as polar lows [e.g., Serreze et al., 1993] are likely present not only in the North Atlantic, but also over the Arctic Ocean where we have limited capability to observe them. Our inability to fully resolve surface wind fields limits our ability to simulate ice motion, deforma- 

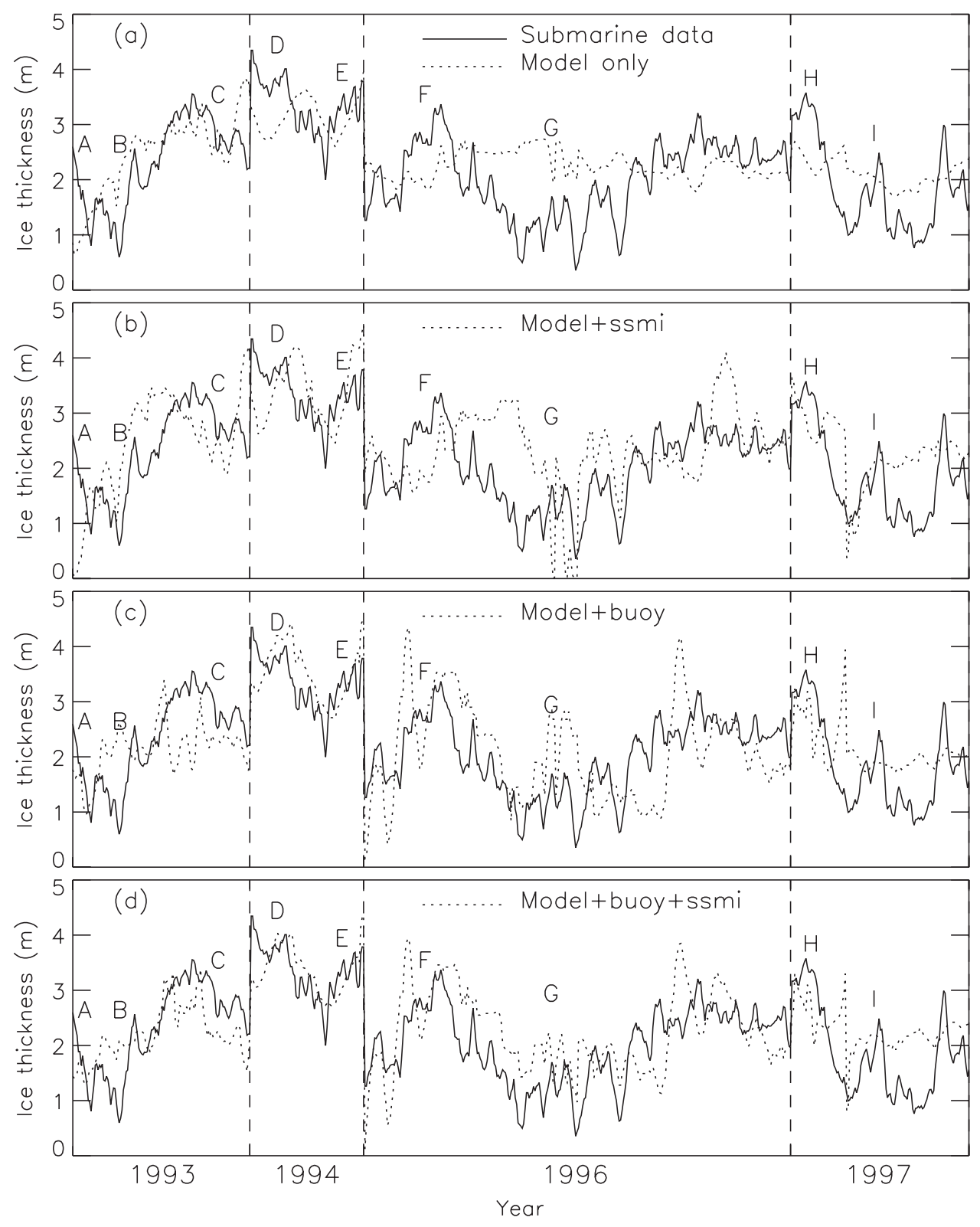

Figure 13. Modeled and observed ice thicknesses along the four submarine cruise tracks in 1993, 1994, 1996, and 1997. The locations of the letters are given in Figure 12.

tion, and thickness. Motion assimilation somewhat mitigates the problem.

[47] It is not clear why buoy assimilation induces sizably more ice volume outflow for 1993 and ice area outflow for 1994 in Fram Strait, in comparison with observations. We speculate that, if the observations are accurate, this may be linked to the correlation length scale $L$ used for OI. Note that for simplicity the length scale was set to be $736 \mathrm{~km}$ throughout the model domain. This value was determined mainly by the model and buoy velocities within the Arctic Basin and may not be suitable for the Fram Strait region. With this predetermined length scale,

Table 5. Comparing Modeled and Observed Ice Thickness (m) Along 1993-1997 Submarine Tracks $^{\mathrm{a}}$

\begin{tabular}{lcccccc}
\hline \multicolumn{1}{c}{ Case } & $\begin{array}{c}\text { Number } \\
\text { of Data }\end{array}$ & $\begin{array}{c}\text { Mean Model } \\
\text { Thickness }\end{array}$ & Bias & $\begin{array}{c}\text { SD of Model } \\
\text { Thickness }\end{array}$ & $\begin{array}{c}\text { Error SD } \\
\left(\sigma_{e}\right)\end{array}$ & $\begin{array}{c}\text { Correlation } \\
(R)\end{array}$ \\
\hline Model only & 639 & 2.39 & 0.18 & 0.50 & 0.76 & 0.45 \\
Model+ssmi & 639 & 2.47 & 0.26 & 0.81 & 0.82 & 0.50 \\
Model+buoy & 639 & 2.28 & 0.07 & 0.83 & 0.77 & 0.57 \\
Model+buoy+ssmi & 639 & 2.37 & 0.16 & 0.70 & 0.66 & 0.65 \\
\hline
\end{tabular}

${ }^{\mathrm{a}}$ Observed thickness has a mean of $2.21 \mathrm{~m}$ and a SD of $0.84 \mathrm{~m}$. 

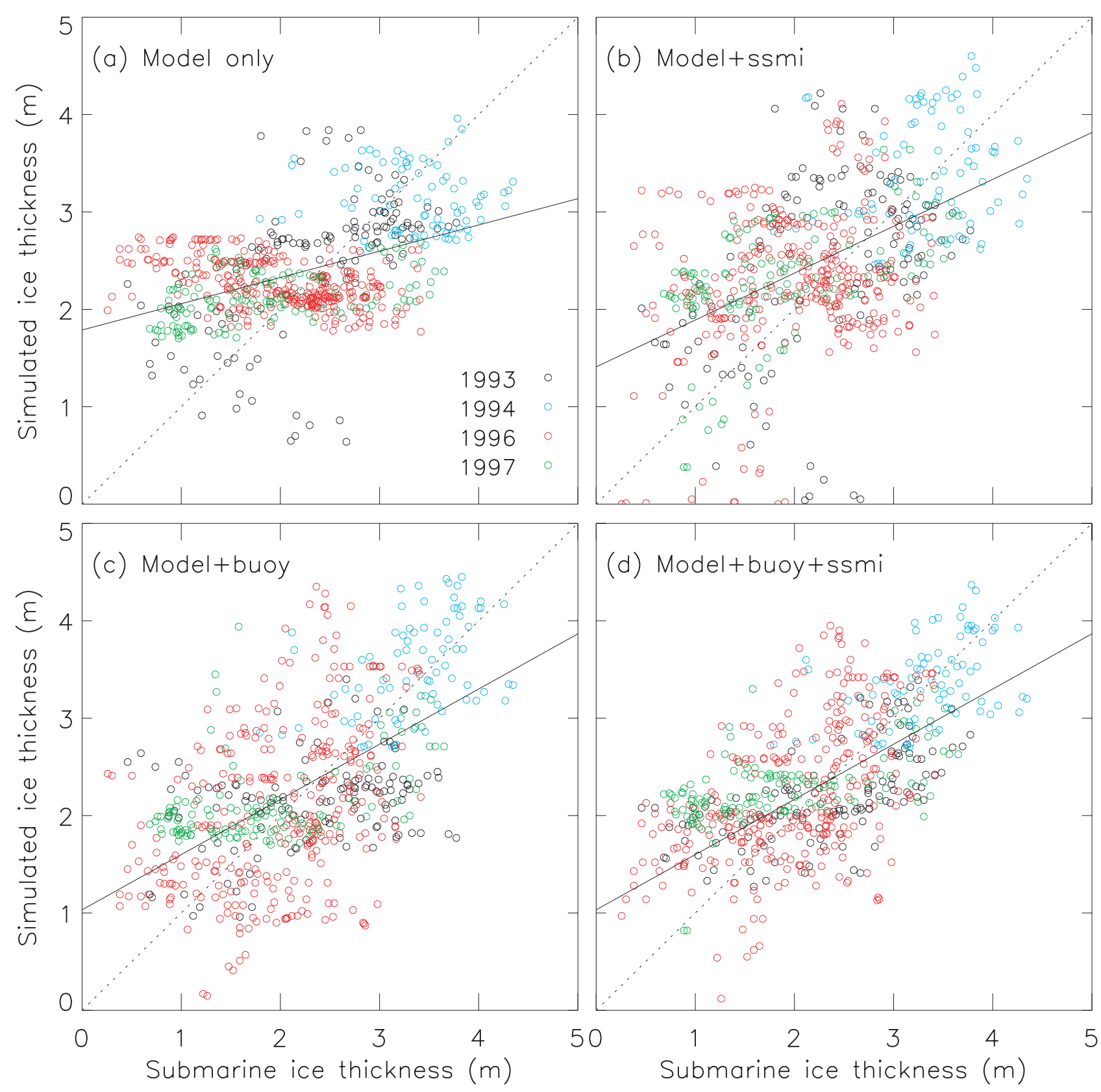

Figure 14. Scatterplot of modeled ice thickness versus observed ice thickness. The solid lines are least squares fits.

assimilating the velocities of often fast-moving buoys in Fram Strait may tend to cause excessive ice speed for some model grid cells, particularly in 1993 and 1994 when there were relatively more buoys exiting Fram Strait. A possible remedy is to determine a new correlation length scale specifically for the Fram Strait region. This regiondependent length scale is likely to be smaller than $736 \mathrm{~km}$ because of the proximity of coastlines. As a result, the long-range influence of the buoys in that region would not be as strong as those inside the Arctic Basin and the simulated ice outflow for 1993 and 1994 may be closer to observations.

[48] Another concern is the area near the Canadian archipelago where we have neither motion nor thickness data, yet assimilation of motion data in the central Arctic Ocean strongly influences ice thickness right up to the coast. We find that if the optimal interpolation-induced velocity component, the second term in equation (4), is not reduced to zero at the model's lateral boundaries, spurious ice build-up occurs along the model coast, particularly near the North Greenland coast and the Canadian Archipelago, as mentioned in Section 3.2. This is in line with Meier and Maslanik's [1999] report of unphysical ice thickness changes in this region. Ice thickness observations from Greenland all along the Canadian Archipelago would be particularly valuable.

[49] Assimilating buoy data offers the most dramatic reduction in the modeled errors in motion. Alone the buoy 
data can cause occasional high local deformation and extreme values of ice thickness. SSM/I motion data tend to mildly subdue the locally high deformation and thickness extrema. They also help the model in the areas where few buoys exist. SSM/I data and buoy data, when jointly assimilated, tend to play complimentary roles. Assimilating both data together gives the best overall performance in simulating ice motion and ice thickness.

[50] Acknowledgments. We thank I. Rigor for providing buoy motion, sea level pressure, and surface air temperature data, $\mathrm{H}$. Stern for careful proofreading and suggestions, R. Moritz for helpful discussions, and A. Schweiger and M. Ortmeyer for computer assistance. We are also grateful for constructive comments from $\mathrm{H}$. Eicken and two anonymous reviewers. Submarine ice thickness data are provided by the National Snow and Ice Data Center. This work was supported by NASA grant NAG5-4375 (for an EOS Interdisciplinary Investigation, POLar Exchange at the Sea surface or POLES), ONR grant N00014-99-1-0742, and NOAA grant NA76GP0508.

\section{References}

Agnew, T., H. Le, and T. Hirose, Estimation of large scale sea ice motion from SSM/I 85.5 Ghz imagery, Ann. Glaciol., 25, 305-311, 1997.

Bourke, R. H., and A. S. McLaren, Contour mapping of Arctic Basin ice draft and roughness parameters, J. Geophys. Res., 97, 17,715-17,728, 1992.

Bryan, K., A numerical method for the study of the circulation of the world oceans, J. Comput. Phys., 4, 347-376, 1969.

Colony, R. L., and I. G. Rigor, International Arctic Ocean Buoy Program data report for 1 January 1992-31 December 1992, Tech. Rep. APL-UW TM 29-93, 215 pp., Appl. Phys. Lab., Univ. of Wash., Seattle, 1993.

Cox, M. D., A primitive equation, three-dimensional model of the oceans, GFDL Ocean Group Tech. Rep. 1, Geophys. Fluid Dyn. Lab./NOAA, Princeton Univ., Princeton, N. J., 1984.

Ebert, E. E., and J. A. Curry, An intermediate one-dimensional thermodynamic sea ice model for investigating ice-atmospheric interactions, J. Geophys. Res., 98, 10,085-10,109, 1993.

Flato, G. M., and W. D. Hibler III, Ridging and strength in modeling the thickness distribution of Arctic sea ice, J. Geophys. Res., 100, 18,611$18,626,1995$.

Hibler, W. D., III, A dynamic thermodynamic sea ice model, J. Phys. Oceanogr., 9, 815-846, 1979.

Hibler, W. D., III, Modeling a variable thickness sea ice cover, Mon. Weather Rev., 1, 1943-1973, 1980.

Hibler, W. D., III, and K. Bryan, A diagnostic ice-ocean model, J. Phys. Oceanogr., 7, 987-1015, 1987.

Ip, C. F., Numerical investigation of different rheologies on sea-ice dynamics, Ph.D. thesis, 242 pp., Dartmouth College, Hanover, N. H., 1993.

Kraus, E. B., and J. S. Turner, A one-dimensional model of the seasonal thermocline: II. The general theory and its consequences, I., Tellus, 19, 98-106, 1967.

Kwok, R., The RADARSAT Geophysical Processor System, Analysis of SAR Data of the Polar Oceans, edited by C. Tsatsoulis and R. Kwok, pp. 235-257, Springer-Verlag, New York, 1998.

Kwok, R., and D. A. Rothrock, Variability of Fram Strait flux and North Atlantic Oscillation, J. Geophys. Res., 104, 5177-5189, 1999.

Kwok, R., A. Schweiger, D. A. Rothrock, S. Pang, and C. Kottmeier, Sea ice motion from satellite passive microwave imagery assessed with ERS SAR and buoy motions, J. Geophys. Res., 103, 8191-8214, 1998.

Lindsay, R. W., Ice deformation near SHEBA, J. Geophys. Res., 107, 8042, 10.1029/2000JC000445, 2002.

Lindsay, R. W., J. Zhang, and D. A. Rothrock, Sea-ice deformation rates from measurements and in a model, Atmos. Oceans, 41, 35-47, 2003.

Liu, A. K., and D. J. Cavalieri, On sea ice drift from the wavelet analysis of the Defense Meteorological Satellite Program (DMSP) Special Sensor Microwave Imager (SSM/I) data, Int. J. Remote Sens., 19, 1415-1423, 1998.
Maykut, G. A., and N. Untersteiner, Some results from a time-dependent thermodynamic model of sea ice, J. Geophys. Res., 76, 1550-1575, 1971.

Meier, W. N., and J. A. Maslanik, Assimilation of observed ice motions into a sea ice thickness distribution model, paper presented at Annual Meeting, Am. Meteorol. Soc., Dallas, Tex., January 10-15, 1999.

Meier, W. N., J. A. Maslanik, and C. W. Fowler, Error analysis and assimilation of remotely sensed ice motion within an Arctic sea ice model, J. Geophys. Res., 105, 3339-3356, 2000.

Moritz, R. E., The ice budget of the Greenland Sea, APL-UW TR 8812, 117 pp., Appl. Phys. Lab., Univ. of Wash., Seattle, 1988.

Parkinson, C. L., and W. M. Washington, A large-scale numerical model of sea ice, J. Geophys. Res., 84, 311-337, 1979.

Pritchard, R. S., M. D. Coon, and M. G. McPhee, Simulation of sea ice dynamics during AIDJEX, J. Press. Vessel Technol., 99J, 491-497, 1977.

Rigor, I. G., R. L. Colony, and S. Martin, Variations in surface air temperature observations in the Arctic, 1979-97, J. Clim., 13, 896-914, 2000.

Rigor, I. G., J. M. Wallace, and R. L. Colony, Response of sea ice to the Arctic Oscillation, J. Clim., 15, 2648-2663, 2002.

Semtner, A. J., Jr., A model for the thermodynamic growth of sea ice in numerical investigations of climate, J. Phys. Oceanogr., 6, 379-389, 1976.

Serreze, M. C., J. E. Box, R. G. Barry, and J. E. Walsh, Characteristics of Arctic synoptic activity, 1952-1989, Meteorol. Atmos. Phys., 51, $147-$ 164, 1993.

Thomas, D. R., and D. A. Rothrock, Blending sequential scanning multichannel microwave radiometer and buoy data into a sea ice model, J. Geophys. Res., 94, 10,907-10,920, 1989.

Thomas, D. R., and D. A. Rothrock, The Arctic Ocean ice balance: A Kalman smoother estimate, J. Geophys. Res., 98, 10,053-10,067, 1993.

Thomas, D. R., S. Martin, D. A. Rothrock, and M. Steele, Assimilating satellite concentration data into an Arctic mass balance model: 19791985, J. Geophys. Res., 101, 20,849-20,868, 1996.

Thorndike, A. S., Kinematics of sea ice, in The Geophysics of Sea Ice, edited by N. Untersteiner, pp. 489-549, Plenum, New York, 1986.

Thorndike, A. S., and R. Colony, Arctic Ocean Buoy Program data report, 19 January 1979-31 December 1979, APL technical report, 131 pp., Appl. Phys. Lab., Univ. of Wash., Seattle, 1980.

Thorndike, A. S., D. A. Rothrock, G. A. Maykut, and R. Colony, The thickness distribution of sea ice, J. Geophys. Res., 80, 4501-4513, 1975.

Vinje, T., N. Nordlund, and A. Kvambekk, Monitoring ice thickness in Fram Strait, J. Geophys. Res., 103, 10,437-10,449, 1998.

Winton, M., A reformulated three-layer sea ice model, J. Atmos. Oceanic Technol., 17, 525-531, 2000.

Zhang, J., A high resolution ice-ocean model with imbedded mixed later, Ph.D. thesis, 229 pp., Dartmouth College, Hanover, N. H., 1993.

Zhang, J., and W. D. Hibler III, On an efficient numerical method for modeling sea ice dynamics, J. Geophys. Res., 102, 8691-8702, 1997.

Zhang, J., and D. A. Rothrock, A thickness and enthalpy distribution seaice model, J. Phys. Oceanogr., 31, 2986-3001, 2001.

Zhang, J., W. D. Hibler III, M. Steele, and D. A. Rothrock, Arctic ice-ocean modeling with and without climate restoring, J. Phys. Oceanogr., 28, $191-217,1998 \mathrm{a}$.

Zhang, J., D. A. Rothrock, and M. Steele, Warming of the Arctic Ocean by a strengthened Atlantic inflow: Model results, Geophys. Res. Lett., 25, $1745-1748,1998$ b.

Zhang, J., D. A. Rothrock, and M. Steele, Recent changes in Arctic sea ice: The interplay between ice dynamics and thermodynamics, J. Clim., 13, 3099-3114, 2000.

R. Kwok, Jet Propulsion Laboratory, California Institute of Technology, Pasadena, CA 91109, USA. (ron.kwok@jpl.nasa.gov)

R. W. Lindsay, D. A. Rothrock, D. R. Thomas, Y. Yu, and J. Zhang, Polar Science Center, Applied Physics Laboratory, College of Ocean and Fishery Sciences, University of Washington, Seattle, WA 98105, USA. (lindsay@apl.washington.edu; rothrock@apl.washington.edu; yanling@ apl.washington.edu; zhang@apl.washington.edu) 